\title{
Red Sea isolation history suggested by Plio-Pleistocene seismic reflection sequences
}

\author{
Neil C. Mitchell ${ }^{1}$, Marco Ligi² ${ }^{2}$ Eelco J. Rohling 3,4
}

${ }^{1}$ School of Earth, Atmospheric and Environmental Sciences, University of Manchester, Williamson Building, Oxford Road, Manchester M13 9PL, UK.

2Istituto Scienze Marine, Consiglio Nazionale delle Richerche, Via Gobetti 101, 40129 Bologna, Italy.

${ }^{3}$ Research School of Earth Sciences, The Australian National University, Canberra, ACT 2611, Australia.

${ }^{4}$ Ocean and Earth Science, University of Southampton, National Oceanography Centre, Southampton SO14 3ZH, UK.

This is a pre-publication version (corrected after peer review) of an article published in the Elsevier journal Earth and Planetary Science Letters: http://dx.doi.org/10.1016/j.epsl.2015.08.037

Keywords: Sea level, seismogram model, chirp sonar, Red Sea, aragonite layers, oxygen isotopes 


\section{Abstract}

High evaporation rates in the desert climate of the Red Sea ensure that, during glacial sea level lowstands when water exchange with the Indian Ocean was more restricted, water salinity and $\delta^{18} 0$ became unusually extreme. Modeling of the effect on Red Sea sedimentary $\delta^{18} 0$ has been used previously to reconstruct relative sea level to $500 \mathrm{ka}$ and now poses the question of whether that sea-level model could be extended if continuous core material of older sediment became available. We attempt to address this question here by examining seismic reflection data. The upper Pleistocene hemipelagic sediments in the Red Sea contain intervals of inorganic aragonite precipitated during supersaturated conditions of sea-level lowstands. Seismic impedance changes associated with boundaries to those aragonite-rich layers appear to explain seismic reflection sequences. A segment of Chirp sediment profiler data from the central Red Sea reveals prominent reflections at $\sim 1, \sim 5, \sim 23, \sim 26$ and $\sim 36$ ms two-way travel time (TWT) from the seabed. Based on depths to the glacial marine isotope stages (MIS) in cores, we relate the upper three reflections to the tops of aragonite-rich layers and hence the sea level rises immediately following MIS 2, 6 and 12. The reflection at $26 \mathrm{~ms}$ is related to an unusually rapid fall into MIS 12 predicted by one sea level reconstruction, which may have created an abrupt lower boundary to the MIS 12 aragonite-rich layer. With the aid of seismogram modeling, we tentatively associate the $\sim 36$ ms reflection with the top of an aragonite-rich layer formed during MIS 16. Furthermore, some segments of lower frequency (airgun and sparker) seismic data from the central and southern Red Sea show a lower (earlier) Plio-Pleistocene (PP) interval that is less reflective than the upper (late) PP interval. This implies less variability in 
sediment impedance and that extreme variability in water salinity did not develop; water exchange with the Indian Ocean likely continued throughout this interval. These results suggest that viable relative sea level reconstructions may be recovered from Red Sea sediment $\delta^{18} 0$ data to at least MIS 16 and perhaps even as far back as the early Pliocene.

\section{Introduction}

The Red Sea is an enclosed water body with a narrow and shallow connection to the Indian Ocean at the Bab el Mandab Strait (Figure 1), with water over the shallowest point at Hanish Sill only 137 m deep at present (Siddall et al., 2003, 2004; Lambeck et al., 2011), limiting exchange of water with the Indian Ocean. Along with extreme net evaporation $\left(2 \mathrm{~m} \mathrm{yr}^{-1}\right)$, the limited replenishment with global ocean water has caused the sea to become more saline (present-day salinity, $S>40 \%$ (Sofianos and Johns, 2007)) than the global ocean. Hypersalinity is prevented by loss of saline Red Sea water and gain of less-saline Indian Ocean water through the strait, the exchange occurring in two layers of differing density, with the Indian Ocean water at the surface and denser Red Sea water beneath it (Maillard and Soliman, 1986; Siddall et al., 2004). Recent assessments of global sea level lowering and regional isostatic responses suggest that water depth over Hanish Sill fell to only 25-33 m during the Last Glacial Maximum (LGM, 20 ka) (Biton et al., 2008; Lambeck et al., 2011). The consequential further reduced water exchange with the Indian Ocean caused the Red Sea to become more saline and supersaturated for aragonite, leading to widespread inorganic aragonite precipitation (Almogi-Labin et al., 1986; Fenton et al., 2000; Milliman et al., 1969; Rohling et al., 1998; and references therein). 
As the effects of seawater evaporation were less compensated by Indian Ocean inflow, this also caused foraminiferal $\delta^{18} 0$ to increase beyond $2 \%$, leading to net glacial-interglacial variations 2-3 times those of the global oceans (Hemleben et al., 1996). Estimates from $\delta^{18} 0$ measurements suggest that $50 \% 0<S<57 \%$ o during the LGM (Biton et al., 2008; Hemleben et al., 1996), or even $S>60 \%$ o (Siddall et al., 2003), in agreement with salinities explaining the disappearance of planktonic foraminifera $(S>49 \%$ ) but continuation of euryhaline pteropods and benthic foraminifera $(S<70 \%$ (Fenton et al., 2000; Fernandes et al., 2006; Rohling et al., 1998), hence water exchange did not stop entirely during the LGM). Late Pleistocene sea-level lowstands in the Red Sea are thus characterized by 'aplanktonic zones', which lack planktonic foraminifera, contain only euryhaline pteropods and benthic foraminifera, and where inorganic aragonite cement is commonplace (Almogi-Labin et al., 1986; Fenton et al., 2000; Milliman et al., 1969; Rohling et al., 1998). In the Red Sea, bottom-water movements are modest (Sofianos and Johns, 2007), aragonite dissolution occurs in interglacials but there is no widespread calcite dissolution (Almogi-Labin et al., 1998; AlmogiLabin et al., 1986), and productivity (and its variability) is low (Trommer et al., 2011).

The impact on sedimentary $\delta^{18} 0$ has been exploited to reconstruct relative sea level (RSL) at Hanish Sill, by coupling hydraulic models for exchange fluxes with the Indian Ocean with known effects of evaporation on isotopic ratios in the sea (Biton et al., 2008; Rohling et al., 2009; Siddall et al., 2003; Siddall et al., 2004). As the sensitivity of $\delta^{18} 0$ to sea level is greatest when the sea is more isolated, the results are particularly useful for reconstructing sea level around lowstands, which are not so well documented from margin sequences (e.g., Miller et al., 
2005), while they are less accurate for highstands. Hanish Sill lies adjacent to the volcanically active Hanish Island and potentially active faults, but a simple adjustment of $\sim 0.02 \mathrm{~m} \mathrm{kyr}^{-1}$ (representing steady sill uplift (Rohling et al., 1998; Rohling et al., 2009; Siddall et al., 2003)) and a further adjustment for hydroisostasy align the Red Sea (Hanish Sill) RSL with global sea level estimates from (i) an independent approach of similar philosophy that uses Mediterranean $\delta^{18} 0$ records (Rohling et al., 2014), (ii) correcting deep-sea benthic foraminiferal $\delta^{18} 0$ for bottom-temperature changes (Elderfield et al., 2012) and (iii) model-based assessment of global deep-sea benthic $\delta^{18} 0$ (Bintanja and van de Wal, 2008), as well as with other sea level estimates such as from some coral elevations and marginal unconformities (see Rohling et al. (2014) and Figure 2). While there are short-lived ( $\sim 10 \mathrm{ky})$ deviations between the Red Sea and the other sea level reconstructions, there are no permanent shifts (Figure 2), so any geological change in elevation of Hanish Sill, if any occurred, would need to have been short-lived and quickly reversed. However, most geological processes are unlikely to reverse within a few ky; we know of no examples of normal fault movements reversing over such timescales in extensional environments such as that considered here. Furthermore, currents measured over Hanish Sill are $\sim 1$ $\mathrm{m} \mathrm{s}^{-1}$ (Pratt et al., 1999), which is too small to cause erosion of bedrock (Mitchell et al., 2012), so any emplaced volcanic materials are unlikely to been fully removed by currents. We therefore prefer to consider the short-period deviations from the other sealevel models in Figure 2 as potentially genuine global variations until proven otherwise. This is important for our interpretation of MIS 12, where there is one such divergence. 
Since no continuous Red Sea sediment cores reach beyond $500 \mathrm{ka}$, it is unknown whether new deep coring could extend the sea-level method to earlier times. The Red Sea method would be attractive because the sea level estimates can be achieved with smaller analytical uncertainty margins than other methods around lowstands (Rohling et al., 2014). Even though systematic uncertainties in the Red Sea results may be enlarged prior to 500 ka (e.g., due to sill elevation uncertainty), a longer Red Sea record would still be useful because the uncertainties are independent of those of the other methods. An approach to narrowing those uncertainties could involve identifying durations in the Red Sea reconstruction where sea level variations are similar to those based on coral, marginal unconformities and deep-sea $\delta^{18} 0$. If those sea level segments are offset but otherwise similar in character, corrections for biases due to geological processes at Hanish Sill can be worked out and applied to the reconstructed RSL, thus yielding intervals older than $500 \mathrm{ky}$ with potential millennial-scale resolution.

In the present article, we describe an assessment of various forms of seismic data collected in the Red Sea, where rapid changes in seawater chemistry associated with sea level variation (Biton et al., 2008; Rohling et al., 2009; Siddall et al., 2003; Siddall et al., 2004) are suggested here to have led to sharp changes in sediment physical properties, producing prominent seismic reflections. In particular, reports of the lowstand aragonite-rich layers describe them as "hard layers", where interconnected fibrous aragonite crystals have left the bulk sediment indurated (Gevirtz and Friedman, 1966; Milliman et al., 1969; Stoffers and Ross, 1974). In our experience, the LGM layer in particular has the consistency of brittle concrete. Such materials can be expected to be more rigid 
and thus to have higher seismic velocity and impedance than surrounding unconsolidated sediment.

The principal data used are from a Chirp sediment profiler. Such systems create records of sub-metre resolution by transmitting long pulses of swept frequency and correlating the recorded echoes with a replica of the transmitted pulse (Dal Forno and Gasperini, 2008; Schock et al., 1989; also see the electronic supplement to this article). We show that many of the variations in reflectivity with depth in the Chirp data are as expected from the estimated history of late Pleistocene global and regional sea level change (Bintanja and van de Wal, 2008; Elderfield et al., 2012; Rohling et al., 2014) and with their anticipated effects on sediment density and velocity.

\section{Variations in sediment physical properties}

Central Red Sea sediments are predominantly hemipelagic carbonate oozes, with varied aeolian dust contributions (Stoffers and Ross, 1974). In order to interpret reflection sequences in the Chirp data, we need indications of how bulk density and P-wave velocity $\left(V_{p}\right)$ vary with depth and age in these sediments. Sediment bulk density measurements for core GeoTü-KL11 (hereafter KL11; Figure 1) shown in Figure 3 reveal high densities around times of the global sea level lowstands MIS 2, 6, 8 and 10 (chronology based on $\delta^{18} 0$ sequences). Some high densities occur in sediment of other than lowstand ages (e.g., high density at $\sim 20 \mathrm{mbsf}$ ). As the core has been sampled, we are unfortunately unable to explore whether these represent systematic changes or are merely caused by, e.g., core disturbance. Nevertheless, high density appears to occur generally where aragonite horizons are expected around lowstands. 
Core GeoTü-KL09 (hereafter KL09) collected close to KL11 (Figure 1) contains similar sediments deposited at a comparable rate. Peaks in Ti/Ca ratio in KL09 (Figure 4) suggest intervals of high deposition fluxes of aeolian dust (Roberts et al., 2011; Grant et al., 2014). In order to correlate those variations with the data of KL11, we identified depths of similar changes in $\delta^{18} 0$. Sediment depths corresponding with times of maximum rate of sea level change of Grant et al. (2014) shown in Figure 3 were thus also marked in Figure 4. Aeolian dust fluxes occur during deglacials around times of maximum sea level change (Roberts et al., 2011). Allowing for some (likely millennial-scale, or $\sim 10 \mathrm{~cm}$ ) imprecision in our correlation between the cores, a major dust interval occurs immediately after MIS10, and roughly coincides with a density minimum of KL11, hence density is reduced there by quartz, clay and other low density dust minerals. Similar dust events occur after MIS2, 6 and 8. However, there are also dust-rich intervals at other times, suggesting a possible origin for some of the variability in density that is not directly related to the $\delta^{18} \mathrm{O}$ curve. Dust fluxes therefore help to explain abrupt transitions in density around lowstands but also the other density variability.

To characterize the sea level effect further, the KL11 bulk density data in Figure $3 b$ were assigned ages using the $\delta^{18} 0$ record shown in Figure 3a. This allowed us to sample sea level from the reconstructions of Rohling et al. (2009) and Bintanja and van de Wal (2008) at ages corresponding with the density data and plot density versus these sea level estimates in Figures $5 \mathrm{a}$ and $5 \mathrm{~b}$. The graphs reveal modest correlations between density and sea level. Effects related to sea level in the Red Sea appear to produce a systematic variation in density, while the dust intervals, density measurement uncertainty, and possible offsets 
in the chronologies assigned to the density data and sea level records produce the uncorrelated variation. The apparent linear variation, however, may disguise a threshold effect of the aragonite abundance in increasing the densities of lowstand sediments (see also Deuser and Degens (1969)).

$V_{p}$ has unfortunately not been measured in these shallow cores. However, the visual appearance of aragonite forming fibrous cements that partially fill porosity in the lowstand sediment intervals and their description by many researchers working on the cores as indurated or "hard layers" (e.g., Gevirtz and Friedman, 1966; Milliman et al., 1969; Stoffers and Ross, 1974) suggests that lowstand sediment is likely to be preferentially rigid (large bulk and shear moduli) and therefore have preferentially larger $V_{p}$. The effect of the dust layers on $V_{p}$ is less clear, as there is no comparable indication of how sediment rigidity varies, although those layers are likely to have somewhat lower $V_{p}$ given the tendency for $V_{p}$ of unconsolidated sediment to correlate with density (Hamilton, 1978). Because of rigidity of the aragonite cement, the aragonite layers are expected to dominate variations in seismic impedance, with dust variations a secondary effect. Hence, we propose interpretations that link reflections to the boundaries of the aragonite layers.

\section{Sediment profiler datasets}

Sediment profiler data were collected on RV Urania in 2005 with a 16transducer Benthos CAP-6600 CHIRP-II system. A Chirp system operates by transmitting a long-duration pulse (here $20 \mathrm{~ms}$ ) with swept frequency (here 2 to $7 \mathrm{kHz}$ ) and processing the reflected signals by correlating them with a replica of the transmitted pulse. The result is a record in which the pulse is effectively 
"compressed" so that the data have very high theoretical resolution (here $\sim 0.1$ ms), with higher energy than would be possible without Chirp processing and greatly increasing signal-to-noise ratio (Schock et al., 1989). We provide more details on the method and its implementation on Urania in the electronic supplement accompanying this article. Figure 6 shows a selection of the data (located on a map of multibeam bathymetry in Figure 7) intended to provide a visual impression of the similarity of the reflection sequence in different locations around Thetis Deep. To highlight the reflection sequences and reveal the draping morphology of the reflections, the data are shown with strong vertical exaggeration (e.g., 31:1 in the case of line TL22Ma). The sea at the time of data collection was moderately rough, making the data appear 'blurred' (e.g., from vessel heave and bubble sweep), but line TL22Ma was collected in a more favorable bearing at lower speed (4-6 knots), so we later focus on it for analyzing the reflection amplitudes.

To broaden the evaluation, we have also considered sediment profiler data collected with a $3.5 \mathrm{kHz}$ (without Chirp) system on RV Conrad in 1984 in the northern Red Sea and stored on paper at Lamont Doherty Earth Observatory (LDEO). A selection of those data and a map of track lines are shown in Figure 8.

\section{Observations}

The Chirp data in Figure 6 all display reflections with a draping morphology typical of pelagic sediments (Mitchell, 1995); sub-bottom reflections follow the seabed reflection at nearly uniform sub-bottom two-way time in each panel. We have deliberately chosen segments of data with this characteristic, but relatively few (roughly $<20 \%$ ) of the data outside the Thetis deep show evidence for 
slumping or other forms of mass-movement. The data do not typically show disrupted stratigraphy characteristics of "seismites" (Bull et al., 2005). In each panel, a zone of strong reflectivity extended by $>2 \mathrm{~ms}$ (R1) extends from the seabed, and below it are 5-10 ms of high reflectivity including a prominent reflection (R2), 10 ms of lower reflectivity, and a strong reflection at 20-30 ms below R1 (R3). Below R3 is another much weaker reflection (R4), followed by a moderately strong reflection another $\sim 10 \mathrm{~ms}$ down (R5). Further but weaker reflections can be observed to sub-seabed $\sim 70$ ms. In Figure 9a, a segment of the clearer TL22Ma record is shown along with (graphs) amplitudes extracted from the data along the right side of the panel (details in figure caption). The graphs in Figure 9a reveal that, in detail, the reflectivity R1 has two peaks, with the deeper peak R1b reaching $86 \%$ of the amplitude of the upper peak R1a. The structure of R1 is also illustrated by the enlarged section taken from the centre of Figure 9a shown in Figure 9c. Reflections R2-R5 have generally declining amplitudes with increasing two-way travel time.

The $3.5 \mathrm{kHz}$ records in Figure 8 all also share prominent and extended seabed reflectivity. In Figure 8c-d and e-f, there is generally an upper reflection sequence (above N1 marked in the figures) with a thickness of $\sim 20 \mathrm{~ms}$ TWT. Below this is a less reflective sequence, until a further prominent reflection N2. However, in general these data do not show as characteristic and repeated a set of reflections as the Chirp data.

\section{Interpretation}

The regional deposition pattern of the hemipelagic sediments is now well characterized by many decades of studies with cores, so we use those results to 
guide our interpretation. The almost constant sedimentation rate with time at KL11 (Figure 3) may be unusual as some variability can be expected given the large dust component of the sediment, which is unlikely to be constant everywhere in the Red Sea (e.g., Figure 4). Figure 10 shows the sediment depths to various glacial isotope stages in the longer continuous sediment cores (Figure 1) plotted versus latitude. The depth spacing between any given pair of isotope stages only modestly varies with latitude. This mimics the locally only modestly varying spacings in TWT between reflections in the Chirp (e.g., 20-25 ms for R3 in Figure 6) and $3.5 \mathrm{kHz}$ sediment profiler data (Figure 8). In airgun seismic data, the total thickness of PP sediments overlying the $\mathrm{S}$ reflection is also somewhat uniform in the central and southern Red Sea away from the coasts and outside the deeps, with a typical interval TWT of 200-250 ms (Ross and Schlee, 1973; Mitchell et al., in press). Collectively, these data suggest that the accumulation of sediments is quasi-uniform pelagic-like, rather than spatiallyvaried as with gravity-driven deposition in depressions (Mitchell, 1995). Although the sediments were deposited on mobile evaporites (Mitchell et al., 2010), except in areas of slope steepening and around faults, the PP layer appears to be passively rafting towards the deep on the evaporites, i.e., tectonics do not complicate the interpretation of the reflections except locally around faults or superficial slumps, which we avoid.

These observations and inferences prompt us to relate variations in properties at similar sediment depths between the core and chirp data. Chirp line TL22Ma is only $34 \mathrm{~km}$ from sediment core MD92-1039 $\left(22^{\circ} 26.240 \mathrm{~N}\right.$, $37^{\circ} 13.150 \mathrm{E}, 1050 \mathrm{~m}$ water depth; Figure 7), where two aplanktonic zones with inorganic aragonite occur: one at 75-142 cm depth, which is rich in cemented 
inorganic carbonate (MIS2, the LGM), and one with finer inorganic carbonate at 450-457 cm depth (MIS6; Fenton et al., 2000). The MIS2 depth roughly agrees with the $\sim 1$-ms separation of R1a and R1b or $\sim 80 \mathrm{~cm}$ at $1600 \mathrm{~m} \mathrm{~s}^{-1}$. R1b thus represents the top of the LGM aragonite-rich layer, whereas R1a corresponds with the seabed (top of the Holocene sediments above the LGM layer). This Holocene thickness is similar to that in cores recovered elsewhere along the Red Sea (Figure 10). The MIS6 depth could then be associated with the deeper reflection at $\sim 5$ ms two-way travel time (TWT) in TL22Ma (R2; Figure 9a). Sedimentologically, MD92-1039 is similar to the more southerly core MD921017 (Figure 1), which contains aplanktonic zones with inorganic aragonite at about 50-85 cm (MIS2), 355-400 cm (MIS6) and 1370-1415 cm (MIS12), and a less extreme zone with inorganic aragonite but some planktonic foraminiferal continuation at $1080-1120 \mathrm{~cm}$ (MIS10). These core chronologies were derived from $\delta^{18} 0$ studies associated with development of the Red Sea sea-level record (Rohling et al., 1998; Rohling et al., 2009; Siddall et al., 2003). Extrapolating using the mean seabed-to-MIS6 deposition rate ratio between MD92-1039 and MD92-1017 ( 1.25), we expect MIS12 at the MD92-1039 location to occur at $\sim 17 \mathrm{~m}$, equivalent to a TWT below seabed of $\sim 21 \mathrm{~ms}$, which is close to reflection R3 at $\sim 23 \mathrm{~ms}$ TWT in TL22Ma (Figure 9). This supports the interpretation of the prominent Chirp reflections as resulting from sharp impedance variations in sediments deposited around times of extreme glacial lowstands. In particular, we suggest that the reflections arise in detail from sharp changes in seismic impedance with depth that arise mainly from the existence of the aragonite-rich layers. As the aragonite-rich sediment was deposited during lowstands of sea 
level, the sediment impedance changes above the aragonite-rich layers correspond with times of rapidly rising sea level.

We have attempted to compare the Chirp reflections more directly with the sea-level reconstructions (Figure 2). Model-based assessment of deep-sea $\delta^{18} \mathrm{O}$ (Bintanja and van de Wal, 2008) suggests that the deepest pre-LGM lowstands occurred at MIS 6, 12 and 16. Deep-sea temperature-corrected $\delta^{18} 0$ (Elderfield et al., 2012) suggests that MIS12 was a particularly deep lowstand, perhaps even deeper than that of the LGM (Figure 2). The Red Sea RSL reconstruction (Grant et al., 2014; Rohling et al., 2009; Siddall et al., 2003) includes an extended MIS12 lowstand that followed an unusually rapid lowering at $\sim 480$ ka (the MIS12 discrepancy with the other sea level reconstructions mentioned earlier). Combined with the depth-distribution (Figure 10) and lithological changes (above) of glacials in Red Sea cores, and correlations between Red Sea sediment density and sea level (Figure 5), this supports an association of Chirp reflections with rapid sea-level changes around lowstands (Figure 9). Thus, reflectivity R1 comprises two peaks R1a and R1b (Figure 9) because Holocene sediments overlie thick, cemented and dense aragonite-rich sediment of the LGM (MIS2). The 1-ms separation of R1a and R1b suggests a Holocene thickness of $\sim 80 \mathrm{~cm}$, which agrees with our logged depths for the MIS2 aplanktonic zone of $\sim 70 \mathrm{~cm}$ in MD92-1039, 35 cm in MD92-1017, 90 cm in GeoTü-KL11, 200 cm in GeoTüKL23, as well as with previous estimates (Locke and Thunell, 1988). Similarly, R2 probably marks the upper edge of the aragonite-rich aplanktonic zone of MIS6 and thus rapid sediment impedance change arising from the ensuing deglaciation. Below that reflection, reflectivity of sediment deposited during other sea-level fluctuations (which have shallower lowstands, Figure 2) is more 
modest, until reaching MIS12. Sediment of MIS10 is not aplanktonic so conditions may not have been so extreme and hence no reflection is assigned to this stage. We interpret the R4-R3 pair of reflections (Figure 9) as associated with aragonite content varying with rapid sea-level fall into the MIS12 glacial stage (R4) and subsequent rapid sea-level rise from abrupt deglaciation (R3). The unusually rapid fall into MIS12 may have left a sharp lower boundary to the aragonite-rich layer, whereas MIS6 may not have created a pair of reflections because the decline in sea level into MIS6 was more gradual (Figure 2), leading to less abrupt changes in aragonite content and seismic impedance. The prominent reflection R5 is attributed to rapid deglaciation following MIS16 (Figure 9; see below). Reflections below R5 have more modest amplitudes and are difficult to assign.

Alternative assignments of the reflections cannot be ruled out unequivocally. For example, the importance of aragonite cements to sediment rigidity and thus impedance may not be as strong as we expect if aragonite replacement during highstands was more important in earlier sediments and thus some reflections may relate instead to dust events. Alternatively, in Figure 9, reflection R3 could have arisen from the top of MIS10 lowstand deposits and thus R4 from the top of MIS12 deposits. However, the latter interpretation would involve an extreme sedimentation rate between MIS10 and MIS12, which is not seen in the base of KL11 (Figure 3) or in other cores (Figure 10), and overall the association shown in Figure 9 seems to us the most compelling.

The northern Red Sea $3.5 \mathrm{kHz}$ profiler data (Figure 8) are more difficult to interpret. From $\delta^{18} \mathrm{O}$ data of Badawi et al. (2005), the upper edges of MIS2, MIS6 and MIS10 lie at 0.6, 7.5 and $19.7 \mathrm{~m}$, respectively, at core site KL23. For seismic 
velocities of $1500-1600 \mathrm{~m} \mathrm{~s}^{-1}$, these would lie at $0.75-0.8,9-10$ and $25-26 \mathrm{~ms}$ below seabed. Thus, the extended seabed reflectivity, which is similar to the extended reflectivity in the central Red Sea Chirp data, is also most likely due to overlapping reflections from both the top of the MIS2 aragonite-rich layer and the top of Holocene sediment overlying it. Given the likely importance of sediment rigidity to seismic impedance, we suspect the other prominent reflections also correspond with aragonite-rich layers. Reflection N1 may therefore correspond with the upper edge of MIS6. Reflection N2, on the other hand, appears generally deeper than 26 ms, so its origins are less certain. MIS6 in core MD76/140 was nearly 50\% shallower below seabed than in KL23 (Figure 10 ), so reflection N1 is also only weakly constrained. Overall, we have found it more difficult to relate the northern Red Sea reflection sequences to the oxygen isotope stages. This could be caused either by different physical properties of the sediments, perhaps from different water chemistry during deposition in the north affected by different climatic conditions (e.g., Biton et al., 2008), or (more likely in our view) from temporally varied deposition rates, such as from varied dust input (Roberts et al., 2011). These issues underline the need for future expeditions to collect long sediment cores coincident with these profiler lines.

\section{Seismogram characterization and modeling}

Seismogram modeling provides a demanding test of the interpretations because gradients in impedance generate reflections, so small errors in data used to generate an impedance series produce exaggerated effects in the models. We consider only relative amplitude changes with TWT. We first examine the reflection amplitudes as they help to inform the seismogram modeling. 


\subsection{Characterization}

Before evaluating the reflection relative amplitudes, we need first to consider how they are likely to be affected by attenuation. Compilations of attenuation measurements (Mitchell, 1993) suggest that attenuation coefficients of $\sim 0.2-2$ $\mathrm{dB} \mathrm{m}^{-1}$ can be expected in the frequency band 2-7 kHz generally, with higher coefficients typical of sandy sediments and lower rates of fine-grained sediments. Tyce (1981) estimated attenuation coefficients using diminishing amplitudes of reflections with varied burial depths recorded with the $4 \mathrm{kHz}$ profiler of the Scripps Deep Tow. His measurements included a very low $0.12 \mathrm{~dB}$ $\mathrm{m}^{-1}$ recorded in calcareous ooze on Carnegie Ridge. Other measurements of Tyce (1981) on terrigenous sediments from the Southern California Borderland clustered around $0.37 \mathrm{~dB} \mathrm{~m}^{-1}$ and those on hemipelagic turbidites from Rockall Trough were $0.19-0.28 \mathrm{~dB} \mathrm{~m}^{-1}$. When we adjust Red Sea reflection amplitudes using $0.12 \mathrm{~dB} \mathrm{~m}^{-1}$, the values appear reasonable (R2 at 17\%, R3 at 15\%, R4 at $9 \%$, and $\mathrm{R} 5$ at $8 \%$ of the amplitude peak of $\mathrm{R} 1 \mathrm{a}$ ). With a $0.4 \mathrm{~dB} \mathrm{~m}^{-1}$ rate, the adjusted values are unrealistic (R5 is $80 \%$ and R4 is $47 \%$ of R1a). Attenuation rates in these sediments therefore are likely closer to the lower end of the published range and we use $0.12 \mathrm{~dB} \mathrm{~m}^{-1}$ in our seismogram modelling below.

Assuming simple planar interfaces, we can roughly evaluate the origins of the reflections as follows. Surface Holocene sediment has a likely bulk density near $1.6 \mathrm{~g} \mathrm{~cm}^{-3}$ (Figure 3) and velocity near $1500 \mathrm{~m} \mathrm{~s}^{-1}$ (Hamilton, 1978), which implies a seabed reflection coefficient of $\sim 0.23$ (dimensionless). Given this coefficient, the second observed near-seabed peak at $86 \%$ of seabed amplitude then implies a reflection coefficient of 0.20 (0.23 times 0.86$)$, which could be 
achieved if the impedance for the LGM sediments were $3600 \mathrm{~g} \mathrm{~m} \mathrm{~cm}^{-3} \mathrm{~s}^{-1}$. If the LGM sediments have a maximum density of $1.9 \mathrm{~g} \mathrm{~cm}^{-3}$ (Figure 3), this impedance suggests that their velocity would be $1895 \mathrm{~m} \mathrm{~s}^{-1}$. This velocity is lower than the regression of Milholland et al. (1980) used in the seismogram modeling described below, but within the range of their values. The deeper reflections are more uncertain because of the attenuation uncertainty, but nevertheless the $15 \%$ of seabed amplitude of the attenuation-adjusted R3 implies a reflection coefficient of 0.035 . This seems low considering the $\sim 0.1 \mathrm{~g} \mathrm{~cm}^{-3}$ shifts in sediment density in Figure 3 (such a density shift alone would produce a reflection coefficient of $\sim 0.06$ ), which suggests that the reflections are caused by gradients in impedance, rather than discrete interfaces, or that other factors reduce amplitudes, such as scattering from interface roughness.

The apparent lack of prominent reflections below R5 (Figure 9) is difficult to evaluate because of attenuation. Nevertheless, at an attenuation rate of $0.12 \mathrm{~dB}$ $\mathrm{m}^{-1}$, a further reflection of the amplitude of R5 at $10 \mathrm{~m}$ greater depth would appear in the Chirp records with amplitude reduced by only $2.4 \mathrm{~dB}$ below R5. In other words, its amplitude would be $76 \%$ of R5. This should be visible and suggests that no further significant reflections exist below R5 in this part of the record. (We suggest that, if Hanish Sill were stable over this earlier interval, this lack of reflectivity would also be compatible with the shallower lowstands older than MIS16 in Figure 2 and hence likely less well-developed aragonite cements in the lowstand sediments.)

\subsection{Seismogram modeling}


The following outlines the stages taken in developing the synthetic seismograms shown in Figure 11. Panels showing the model impedance, reflectivity series and simulated seismograms are shown in the electronic supplement Figure S5. $V_{p}$ values were needed to compute sub-bottom depths and seismic impedance (equal to velocity times wet bulk density). In the absence of reliable velocity data for Red Sea sediments, we employed an empirical relationship of Milholland et al. (1980) between bulk density and velocity derived from DSDP Site 289 samples that included calcareous ooze, chalk, and limestone. Those samples included some from below $200 \mathrm{~m}$ sediment depth, but the derived relationship was considered useful here, rather than relationships for less consolidated sediments (e.g., Hamilton, 1978), because of the lithified aragonite-rich layers in the Red Sea sediments. The relationship was based on sample densities extending down to $1.6 \mathrm{~g} \mathrm{~cm}^{-3}$, overlapping with the KL11 densities, but likely over-estimates velocity for the less consolidated sediment components. As the seismogram analysis involves computing gradients in seismic impedance rather than absolute values, the main effect of exaggerated velocity variability will be generally over-estimated reflection coefficients. Furthermore, sub-bottom depths are computed with sedimentation rates adjusted to ensure that the modeled series matches the TL22Ma data series (i.e., a free parameter), so velocity bias is not a major concern for depth conversion. The resulting impedance varies with sea level as shown in Figure 5c.

Because the presence or absence of the shallow inorganic aragonite-rich layers is caused by sea-level variation around lowstands, we used the regression shown in Figure 5c (red line) to convert the sea-level records in Figure 2 to sediment impedance records. The impedance series in each case was converted 
to a reflection coefficient series using the Zoeppritz equations (e.g., Telford et al. (1976)). Note that the reflection coefficient values are effectively gradients because the impedance series is a discretized representation of a continuous variable, hence the units given in Figure S5 are $\mathrm{ms}^{-1}$. The use of a linear relationship such as that in Figure 5c ignores possible threshold effects of sea level on aragonite precipitation, so it only roughly represents the variation in impedance for sediment deposited around sea level lowstands. The model impedance variability for sediment deposited at other times, particularly around sea level highstands, may reproduce the observed Chirp data reflectivity only fortuitously (reflectivity there may be more likely caused by the varied dust input and other factors mentioned earlier).

To produce a model seismogram, the reflection series needs to be convolved with a source wavelet. Given that the Urania Chirp signal compression effectively generates a Klauder wavelet in the recorded data (Dal Forno and Gasperini, 2008), we generated this source wavelet from the 2-7 kHz frequency sweep and $20 \mathrm{~ms}$ pulse duration. Convolving that wavelet with the various reflection coefficient series produced model seismograms.

Chirp sediment profilers, including that on Urania (Dal Forno and Gasperini, 2008), typically record only a continuous record of the mean peak amplitude or magnitude of the reflected signal, not the full waveform. We derived the relative variation in peak amplitude by rectifying the modeled waveform (converted all negative values to positive values) and filtering the resulting all-positive data with a $1 \mathrm{~ms}$ cosine-tapered filter (Wessel and Smith, 1991). This process was repeated with the reflection series attenuated by 0.12 $\mathrm{dB} \mathrm{m}^{-1}$ (two-way travel distance, i.e., $0.24 \mathrm{~dB} \mathrm{~m}^{-1}$ from the seabed) to produce 
the output shown by the bold lines in Figures 11b-11d. Figures 11a and 11e show the reflection amplitudes (\% of R1a) in TL22Ma for comparison. In the models, impedance contrast at the seabed is a change over an infinitesimal distance, whereas the reflection series represent impedance gradients versus TWT. Hence, trends in modeled and observed reflection amplitudes should be compared, not values with respect to seabed.

The synthetic seismogram amplitudes computed from the KL11 data decrease by around half with depth ( 3 to $15 \mathrm{~ms}$ ), similar to TL22Ma (Figure S5b), but it is difficult to associate individual reflections to particular isotope stages in KL11. KL11 contains low carbonate contents compared with oceanic carbonate oozes (e.g., >90\% in some shallow or equatorial Pacific sediments; Berger et al., 1976), due to the strong aeolian dust fluxes that affect cores throughout the Red Sea (e.g., Roberts et al. (2011)). The imperfect match in Figure S5b likely arises from varied aeolian inputs, which differ in variability and phase from sea-level changes (Roberts et al., 2011).

To produce the seismogram model in Figure 11c, an impedance-versus-age model derived from the sea level reconstruction of Bintanja and van de Wal (2008) and the regression in Figure 5c was converted to impedance versus twoway time using a constant sedimentation rate chosen so that the termination of MIS12 coincided with the TWT of R3. This sea-level curve is smoother than the KL11 density data, so simulated reflection amplitudes are smaller in Figure 11c than in Figure 11b. Because the sea-level rise of the MIS12 termination is gradual in the record of Bintanja and van de Wal (2008), and interference between reflected positive and negative excursions in the high-frequency compressed Chirp wavelet (Figure S5a) overlap, leading to destructive 
interference, the predicted reflection is weak relative to observed R3 in TL22Ma. Gradual sea level lowering into MIS12 in this record also produces only a weak simulated reflection. In contrast, a prominent reflection is simulated for the termination of MIS6 and is comparable in relative amplitude with R2.

A similar model employing the Red Sea RSL (Rohling et al., 2009) is shown in Figure S5d. Compared with Figure S5c, this better approximates the general downward reflectivity decline. Again, a strong reflection is predicted at the termination of MIS6 and is comparable in amplitude (relative to surrounding reflectivity) with R2. Moreover, the extended MIS12 sea-level lowstand in the Rohling et al. (2009) sea level reconstruction yields a 2-ms interval of low reflection coefficients bounded by large reflection coefficients for both the sea level lowering into MIS12 and the rise at its termination, in agreement with R4 and R3 in TL22Ma, respectively.

The potential thresholds of aragonite growth ignored in our use of the linear relationship between seismic impedance and sea level could be accounted for in the modelling if new long cores become available so that continuous logs can be compared with spatially coincident geophysical data. Nevertheless, with this present limitation in mind, we evaluated the nature of R5, by extending the impedance record based on the Rohling et al. (2009) RSL reconstruction to below 27.85 ms TWT using the impedance values computed from the Bintanja and van de Wal (2008) model, and then adjusting the post-MIS16 impedance gradient until the modeled amplitude ratio of R5 to R3 agreed with that in TL22Ma. In our best-fitting modified model shown by the solid blue line in Figure 11d, the post-glacial stage of MIS16 is equivalent to a sea level rise of 53 $\mathrm{m} \mathrm{kyr}^{-1}$, whereas the green and turquoise lines show the effects of sea level rise 
half or double this rate (these lines are only partly visible as they underlie the blue curve). A sedimentation rate $60 \%$ larger than that of the seabed to MIS12 was used below MIS12 in order to match the R5 TWT. This may seem arbitrary but there are no other events in the sea level curve to explain R5 if R4 and R3 are as we suggest and this change in sedimentation rate is not uncommon in marine sediments. Given the likely non-linear relationship between impedance and sea level, the $53 \mathrm{~m} \mathrm{kyr}^{-1}$ post-MIS16 sea-level rise represents a high-end estimate. It nevertheless lies within the range of core-based estimates for four more recent deglaciations (Grant et al., 2014). A tentative low-end estimate can also be made from ratios of the observed amplitudes. Corrected for attenuation, the amplitude of R5 is half that of R3, so the impedance gradient above the lowstand sediment is probably comparable (within a factor of two) with that for MIS12. Hence, the post-MIS16 sea level rise was likely also not much slower than that after MIS12 in the Red Sea reconstruction (Rohling et al., 2009), which occurred at $22 \mathrm{~m} \mathrm{kyr}^{-1}$ (Grant et al., 2014).

\section{Discussion}

\subsection{Utility of the characteristic Chirp reflection sequences}

The presence of common reflection sequences in the Chirp data that apparently correspond with the sea level reconstructions suggests that these data could be useful to guide future long-coring campaigns in the Red Sea. For example, if earlier (MIS16-age) samples are sought, these are more likely to be recoverable where reflection $\mathrm{R} 5$ is closer to the bed and within coring depth.

The chronostratigraphic nature of the reflections will also allow spatial variations in deposition rate across the area to be characterized. For example, in 
the small selection in Figure 6, reflection R3 lies at 19.3, 19.0, 25.8, 19.6, 19.5, $17.7,18.9,18.8,18.5,18.7$ and 25.3 ms below seabed (segments 18j to TL25Mb in row order). Thus, R3 lies at an almost uniform $\sim 19 \mathrm{~ms}$ except for two areas where it lies at >25 ms: segments $18 \mathrm{~m}$ and TL25Mb. From Figure 7, TL25Mb lies in a deeper area, where preferential accumulation of particles ("focusing") is likely (Mitchell, 1995), but excess deposition in segment 18m is less obviously explained. The deep-water hemipelagic sediments of the Red Sea are widely considered not to have been affected by bottom currents, as deep-water movements are presently modest (Sofianos and Johns, 2007). Depth-dependent dissolution of carbonates is also unknown. Spatial variations in deposition rate, however, suggest that there are some influences on deposition that should be investigated in order to understand this sedimentary system better.

\subsection{Isolation history of the earlier Plio-Pleistocene}

Given the apparent correspondence between the Chirp reflectivity sequence and the sequence of lowstand stages in the sediments (and, thus, sea level), we have also examined available airgun and sparker seismic data from the Red Sea, which provide information as far back as the early Pliocene, following the end of the Miocene evaporite stage, though with lower resolution. There has been no evidence in the literature, as far as we are aware, of a major isolation of the Red Sea during the Pliocene or Pleistocene (e.g., Hughes and Beydoun, 1992). Whereas some "hard layers" have been reported in sediment at the DSDP sites older than 1 Ma (Stoffers and Ross, 1974), i.e., deposited before the MidPleistocene Transition, no evaporite minerals were reported (see electronic supplement Figure S8 for estimated age distribution of these layers). However, 
the DSDP cores were recovered by rotary drilling and left $40 \%, 66 \%$ and $44 \%$ of the sections not sampled at sites 225, 227 and 228, respectively (Whitmarsh et al., 1974), so cemented layers may conceivably remain undetected. Seismic reflection data are potentially useful for addressing this issue because, in our view, rigid lithified layers would likely produce observable reflections, if more than about a quarter of a wavelength in thickness.

The assessment is described in the electronic supplement. Unfortunately, the best spatial distribution is provided by older seismic data in only paper form. However, we suggest it is possible to assess whether any given reflection amplitude is larger or smaller than another (at a common survey time and shot, so that the data have the same fixed gain). Physical property data from the DSDP cores suggest that the reflection coefficient of the top of the evaporites $(\sim 0.38)$ is similar to that of the seabed reflection $(\sim 0.29-0.41)$. This allows us to assess whether declining reflectivity with depth and two-way time is caused by attenuation not compensated adequately by any applied time-varied gain (TVG), or if it has a geological origin (i.e., a prominent evaporite reflection that is comparable with the seabed reflection implies that the section is adequately compensated by the TVG for attenuation).

Many of the records show strong reflectivity in their upper Plio-Pleistocene (PP) sections, which seems readily explainable by the varied aeolian dust input and by the aragonite-rich layers of the late Pleistocene. Stoffers and Ross (1974) noted that the terrigenous component increases with depth into the Pliocene in the DSDP cores. We observe some segments of the lower PP that are reflective and others that are transparent. The reflective segments probably represent deposits that also have a varied terrigenous component. We suggest, however, 
that the transparent segments likely represent sediments of more uniform seismic impedance and thus confirm that no thick lithified layers are present. If the dominant frequency of these records is $\sim 100 \mathrm{~Hz}$, this implies no lithified layers are present thicker than about five metres and commensurably thinner intervals in higher frequency seismic data.

In some parts of the Red Sea, the upper PP has been removed by erosion, so we can see how the character of the lower PP appears where it rises towards the seabed reflection (and hence where attenuation and/or TVG are less of an issue). One such example is shown in digital multichannel seismic data in Figure 11 of Ehrhardt and Hübscher (2015). Although distorted by a possible Automatic Gain Control applied to the section, which may have suppressed amplitudes above the prominent $S$ reflection from the evaporites (C. Hübsher and A. Ehrhardt, pers. comm., 2015), there is no similar prominent reflection within the lower PP. We show two further examples in sparker data in the electronic supplement. Associated with the erosion, the seabed reflection and S reflection both show reduced coherence in these areas, probably a result of scattering loss from a more rugged seabed. However, as the $\mathrm{S}$ reflection is nevertheless observable, we suggest the transparent layer is genuine. These data therefore reinforce the view from the DSDP core analyses (Stoffers and Ross, 1974) that exchange with the Indian Ocean continued throughout the Pliocene following the end of the Miocene evaporite phase.

Whether Hanish Sill was stable over this interval is unknown. Indeed, there has been volcanic activity on the adjacent Hanish-Zuqar islands and Eritrean coast (Gass et al., 1973). Tectonic movements are also possible given the extensional environment, although present day extension across Hanish Sill is 
negligible in GPS repeat survey data (Reilinger et al., 2015) and seafloorspreading magnetic anomalies to Chron 3 (4-5 Ma) are interpretable at $16^{\circ} \mathrm{N}$ in the Red Sea, but become confused south of $15^{\circ} 30^{\prime} \mathrm{N}$ and disappear entirely south of $15^{\circ} \mathrm{N}$, where tectonic displacement has transferred to the Danakil Depression (Eagles et al., 2002; also see Figure 1). We suggest that tectonic and volcanic effects on the sill elevation are more likely to have been episodic than continuous. If the sill were stable or at least lay near its present depth, continuous exchange with the Indian Ocean would be compatible with the sea levels reconstructed from deep ocean $\delta^{18} 0$ (Bintanja and van de Wal, 2008; Elderfield et al., 2012), which do not contain deep drawdowns prior to the midPleistocene transition (0.7-1.25 Ma). Thus, continuous sediment $\delta^{18} 0$ older than 500 ka could potentially provide useful sea level records for the Pliocene and earlier Pleistocene. To account for some movement of the sill, sea level reconstruction from sedimentary $\delta^{18} 0$ data could involve identifying segments of the Red Sea reconstruction that are similar in character to those reconstructed from deep ocean $\delta^{18} 0$ and other data, while using offsets from the latter to correct for sill movement or other events that have modified the strait outside of those intervals.

\section{Conclusions}

"Hard layers" that contain inorganic aragonite precipitated during sealevel lowstands are suggested to explain sequences of Chirp reflections in the central Red Sea. We have developed an interpretation based on depths to such layers recorded in sediment core data, with apparent correspondence between the reflection sequence and times of rapid changes in sea level around lowstands, 
which likely marked the transitions to/from aragonite precipitation. A seismogram model developed to reproduce the Chirp reflection sequence involves a constant sediment deposition rate from MIS12 to present but a rate 60\% larger below MIS12 in order to match the two-way time to MIS16.

Although this interpretation needs to be verified with a coincident core, we note several interesting features of the interpretation for sea level studies. The Red Sea reconstruction (Rohling et al., 2009) includes an abrupt early decline into MIS12 at $\sim 480 \mathrm{ka}$, whereas other reconstructions based on deep-ocean $\delta^{18} 0$ (Bintanja and van de Wal, 2008; Elderfield et al., 2012) infer only a gradual decline. We have interpreted double reflection R3-R4 as caused by both abrupt upper and lower boundaries to MIS12, with the lower reflection caused by an unusually abrupt lower boundary to the lowstand aragonite layer. This would favour the reconstruction of Rohling et al. (2009). Furthermore, the attenuationcorrected amplitude of R5 is half that of R3, suggesting that the impedance gradient above the MIS16 lowstand sediments is not much different (within about a factor of two) from that of MIS12. In turn, this may suggest that the rate of sea level rise following MIS16 was comparable to that following MIS12.

Airgun and sparker reflection data allow assessment of the lower PlioPleistocene. If the Red Sea had become sufficiently isolated to leave $\sim 5 \mathrm{~m}$ thickness of lithified sediment, this should be detectable in $100 \mathrm{~Hz}$ seismic data (and commensurably thinner intervals would be obvious in higher frequency data). The lack of notable reflections in the generally transparent layers of the lower Plio-Pleistocene therefore suggest that the Red Sea was persistently open to the Indian Ocean through this interval, in agreement with the lack of deep 
(>100 m) sea-level lowstands shown by long sea-level reconstructions

(Elderfield et al, 2012; Bintanja and van de Wal, 2008).

\section{Acknowledgements}

Permissions of the governments of Egypt, Sudan and Saudi Arabia to carry out the survey on RV Urania are gratefully acknowledged. The Urania cruise was funded by the Consiglio Nazionale delle Ricerche under project LEC-EMA21F of the European Science Foundation programme EUROMARGINS (contract ERASCT-2003-980409 of the European Commission, DG Research FP6). Figures in this article were created with the "GMT" software system. The density and carbonate data for KL11 (Figure 3) were kindly provided by Christoph Hemleben. We thank Rose-Anne Weissel of LDEO for scanning the $3.5 \mathrm{kHz}$ records in Figure 8 and for help with scanning the Conrad RC0911 records (originally collected by Tom Aitken). Peter Feldens kindly provided segments of sparker seismic data shown in electronic supplement Figure S7. Christian Hübscher and Axel Ehrhardt provided helpful clarification of seismic data from the northern Red Sea. We thank three anonymous reviewers and editor Martin Frank for helpful comments. EJR acknowledges support from 2012 Australian Laureate Fellowship FL120100050. ML acknowledges supporting grant PRIN 20125JKANY_002.

\section{References}

Almogi-Labin, A., Hemleben, C., Meischner, D., 1998. Carbonate preservation and climate changes in the central Red Sea during the last $380 \mathrm{kyr}$ as recorded by pteropods. Mar. Micropal. 33, 87-107. 
Almogi-Labin, A., Luz, B., Duplessy, J.C., 1986. Quaternary paleo-oceanography, pteropod preservation and stable-isotope record of the Red Sea. Palaeogeog., Palaeoclim. Palaeoecol. 57, 195-211.

Badawi, A., Schmiedl, G., Hemleben, C., 2005. Impact of late Quaternary environmental changes on deep-sea benthic foraminiferal faunas of the Red Sea. Mar. Micropal. 58, 13-30.

Berger, W.H., Adelseck, C.G., Mayer, L.A., 1976. Distribution of carbonate in surface sediments of the Pacific Ocean. J. Geophys. Res. 81, 2617-2627.

Bintanja, R., van de Wal, R.S.W., 2008. North American ice-sheet dynamics and the onset of 100,000-year glacial cycles. Nature 454, 869-872.

Biton, E., Hildor, H., Peltier, W.R., 2008. Red Sea during the Last Glacial Maximum: Implications for sea level reconstruction. Paleocean. 23, paper PA1214, doi:1210.1029/2007PA001431.

Bull, J.M., Minshull, T.A., Mitchell, N.C., Dix, J.K., Hardardottir, J., 2005. Magmatic and tectonic history of Iceland's western rift zone at Lake Thingvallavatn. Geol. Soc. Am. Bull. $117,1451-1465$.

Dal Forno, G., Gasperini, L., 2008. ChirCor: A new tool for generating chirp-sonar seismograms. Comput. Geosc. 34, 103-114.

Deuser, W.G., Degens, E.T., 1969. $\mathrm{O}^{18} / \mathrm{O}^{16}$ and $\mathrm{C}^{13} / \mathrm{C}^{12}$ ratios of fossils from the hotbrine deep area of the central Red Sea, in: Degens, E.T., Ross, D.A. (Eds.), Hot brines and recent heavy metal deposits in the Red Sea. Springer-Verlag, New York, pp. 336-347.

Eagles, G., Gloaguen, R., Ebinger, C., 2002. Kinematics of the Danakil microplate. Earth Planet. Sci. Lett. 203, 607-620.

Ehrhardt, A., Hübscher, C., 2015. The northern Red Sea in transition from rifting to 
drifting - Lessons learned from ocean Deeps, in: Rasul, N.M.A., Stewart, I.C.F. (Eds.), The Red Sea: The formation, morphology, oceanography and environment of a young ocean basin. Springer-Verlag, Berlin Heidelberg, pp. 99-121.

Elderfield, H., Ferretti, P., Greaves, M., Crowhurst, S., McCave, I.N., Hodell, D., Piotrowski, A.M., 2012. Evolution of ocean temperature and ice volume through the Mid-Pleistocene Climate Transition. Science 337, 704-709.

Fenton, M., Geiselhart, S., Rohling, E.J., Hemleben, C., 2000. Aplanktonic zones in the Red Sea. Mar. Micropal. 40, 277-294.

Fernandes, C.A., Rohling, E.J., Siddall, M., 2006. Absence of post-Miocene Red Sea land bridges: biogeographic implications. J. Biogeography 33, 961-996.

Gass, I.G., Mallick, D.I.J., Cox, K.G., 1973. Volcanic islands of the Red Sea. Journal of the Geologic Society 129, 275-310.

Gevirtz, J.L., Friedman, G.M., 1966. Deep-sea carbonate sediments of the Red Sea and their implications on marine lithification. J. Sediment. Petrol. 36, 143-151.

Grant, K.M., Rohling, E.J., Bronk Ramsey, C., Cheng, H., Edwards, R.L., Florindo, F., Heslop, D., Marra, F., Roberts, A.P., Tamisiea, M.E., Williams, F., 2014. Sealevel variability over five glacial cycles. Nature Communications Art. 5076, doi:10.1038/ncomms6076.

Hamilton, E.L., 1978. Sound velocity-density relations in sea-floor sediments and rocks. J. Acoust. Soc. Am. 63, 366-377.

Hemleben, C., et al., 1996. Three hundred eighty thousand year long stable isotope and faunal records from the Red Sea: Influence of global sea level change on hydrography. Paleoceanography 11, 147-156.

Hughes, G.W., Beydoun, Z.R., 1992. The Red Sea - Gulf of Aden: biostratigraphy, lithostratigraphy and palaeoenvironments. J. Petrol. Geol. 15, 135-156. 
Lambeck, K., Purcell, A., Flemming, N.C., Vita-Finzi, C., Alsharekh, A.M., Bailey, G.N., 2011. Sea level and shoreline reconstructions for the Red Sea: isostatic and tectonic considerations and implications for hominin migration out of Africa. Quat. Sci. Rev. 30, 3542-3574.

Locke, S., Thunell, R.C., 1988. Paleoceanographic record of the last glacial/interglacial cycle in the Red Sea and Gulf of Aden. Palaeogeog., Palaeoclim. Palaeoecol. 64, 163-187.

Maillard, C., Soliman, G., 1986. Hydrography of the Red Sea and exchanges with the Indian Ocean in summer. Oceanologica Acta 9, 249-269.

Milholland, P., Manghnani, M.H., Schlanger, S.O., Sutton, G.H., 1980. Geoacoustic modelling of deep-sea carbonate sediments. J. Acoust. Soc. Am. 68, 1351-1360.

Miller, K.G., Kominz, M.A., Browning, J.V., Wright, J.D., Mountain, G.S., Katz, M.E., Sugarman, P.J., Cramer, B.S., Christie-Blick, N., Pekar, S.F., 2005. The Phanerozoic record of global sea-level change. Science 310, 1293-1298.

Milliman, J.D., Ross, D.A., Ku, T.-L., 1969. Precipitation and lithification of deep-sea carbonates in the Red Sea. J. Sed. Petrol. 39, 724-736.

Mitchell, N.C., 1993. A model for attenuation of backscatter due to sediment accumulations and its application to determine sediment thickness with GLORIA sidescan sonar. J. Geophys. Res. 98, 22477-22493.

Mitchell, N.C., 1995. Diffusion transport model for pelagic sediments on the MidAtlantic Ridge. J. Geophys. Res. 100, 19,991-920,009.

Mitchell, N.C., Ligi, M., Farrante, V., Bonatti, E., Rutter, E., 2010. Submarine salt flows in the central Red Sea. Geol. Soc. Am. Bull. 122, 701-713.

Mitchell, N.C., Huthnance, J.M., Schmitt, T., Todd, B., 2012. Threshold of erosion of submarine bedrock landscapes by tidal currents. Earth surface processes and landforms 38, 
627-639.

Mitchell, N.C., Ligi, M., Feldens, P., Hübscher, C., in press. Deformation of a young salt giant: regional topography of the Red Sea Miocene evaporites. Basin Res. http://dx.doi.org/10.1016/j.eps1.2015.08.037

Pratt, L.J., Johns, W., Murray, S.P., Katsumata, K., 1999. Hydraulic interpretation of direct velocity measurements in the Bab el Mandab. J. Phys. Ocean. 29, 27692784.

Rabineau, M., Berné, S., Olivet, J.-L., Aslanian, D., Guillocheau, F., Joseph, P., 2006. Paleo sea levels reconsidered from direct observation of paleoshoreline position during Glacial Maxima (for the last 500,000 yr). Earth Panet. Sci. Lett. 252, 119137.

Reilinger, R., McClusky, S., ArRajehi, A., 2015. Geodetic constraints on the geodynamic evolution of the Red Sea, in: Rasul, N., Stewart, I.C. (Eds.), The Red Sea: The formation, morphology, oceanography and environment of a young ocean basin. Springer-Verlag, Berlin Heidelberg, 99-121.

Roberts, A.P., Rohling, E.J., Grant, K.M., Larrasoaña, J.C., Liu, Q., 2011. Atmospheric dust variability from Arabia and China over the last 500,000 years. Quat. Sci. Rev.30, 3537-3541.

Rohling, E.J., Fenton, M., Jorissen, F.J., Bertrand, P., Ganssen, G., Caulet, J.P., 1998. Magnitudes of sea-level lowstands of the past 500,000 years. Nature 394, 162-165. Rohling, E.J., Foster, G.L., Grant, K.M., Marino, G., Roberts, A.P., Tamisiea, M.E., Williams, F., 2014. Sea-level and deep-sea-temperature variability over the past 5.3 million years. Nature 508, 477-482.

Rohling, E.J., Grant, K., Bolshaw, M., Roberts, A.P., Siddall, M., Hemleben, C., Kucera, M., 2009. Antarctic temperature and global sea level closely coupled over 
the past five glacial cycles. Nature Geosci. 2, 500-504.

Ross, D.A., Schlee, J., 1973. Shallow structure and geologic development of the southern Red Sea. Geol. Soc. Am. Bull. 84, 3827-3848.

Schock, S.G., LeBlanc, L.R., Mayer, L.A., 1989. Chirp subbottom profiler for quantitative sediment analysis. Geophysics 54, 445-450.

Siddall, M., Rohling, E.J., Almogi-Labin, A., Hemleben, C., Meischner, D., Schmeizer, I., Smeed, D.A., 2003. Sea-level fluctuations during the last glacial cycle. Nature $423,853-858$.

Siddall, M., Smeed, D.A., Hemleben, C., Rohling, E.J., Schmeizer, I., Peltier, W.R., 2004. Understanding the Red Sea response to sea level. Earth Panet. Sci. Lett. 225, $421-434$.

Sofianos, S.S., Johns, E.W., 2007. Observations of the summer Red Sea circulation. J. Geophys. Res. 112, Paper C06025, doi:06010.01029/02006JC003886.

Stoffers, P., Ross, D.A., 1974. Sedimentary history of the Red Sea. in: Whitmarsh, R.B., O.E. Weser, D.A. Ross, et al., Initial reports of the Deep Sea Drilling Project U.S. Government Printing Office 23, 849-865.

Telford, W.M., Geldart, L.P., Sheriff, R.E., Keys, D.A., 1976. Applied Geophysics. Cambridge University Press, New York.

Trommer, G., Siccha, M., Rohling, E.J., Grant, K., van der Meer, M.T.J., Schouten, S., Baranowski, U., Kucera, M., 2011. Sensitivity of Red Sea circulation to sea level and insolation forcing during the last interglacial. Clim. Past Discuss. 7, 1195-1233. Tyce, R.C., 1981. Estimating acoustic attenuation from a quantitative seismic profiler. Geophysics 46, 1364-1378.

Wessel, P., Smith, W.H.F., 1991. Free software helps map and display data. Eos, Transactions, American Geophysical Union 72, 441. 
Whitmarsh, R.B., Weser, O.E., Ross, D.A., 1974. Initial Reports of the Deep Sea Drilling Project, 23B. U. S. Government Printing Office, Washington, D. C.

\section{Figures}




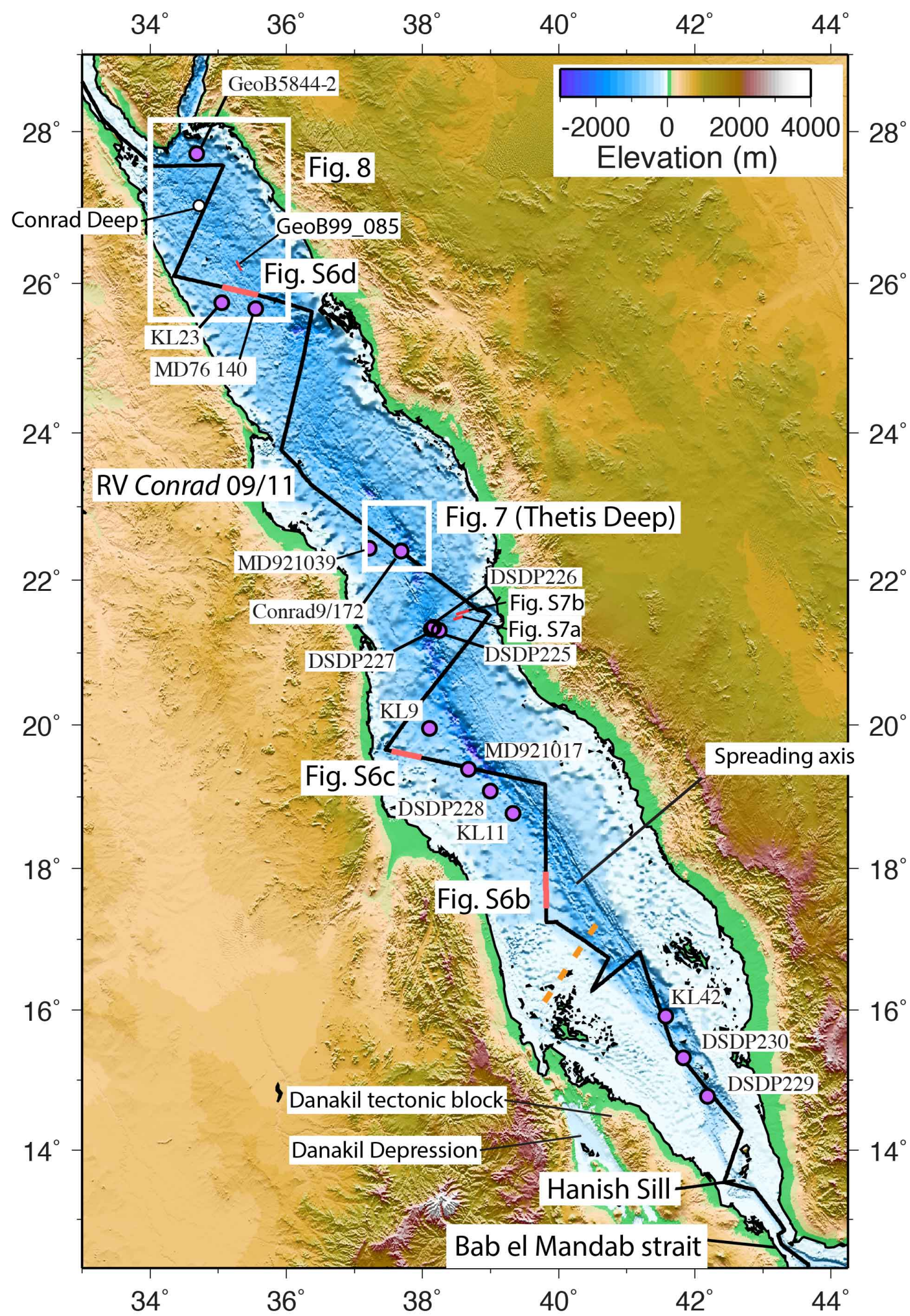

Figure 1. Overview map of the Red Sea, including locations of a selection of core sites (purple circles with small lettering), track of RV Conrad cruise RC0911 (solid black line) and locations of Figures 7 and 8 . Also marked in red are 
seismic line GeoB99_085 (Ehrhardt and Hübscher, 2015) and survey lines corresponding to seismic data shown in electronic supplement Figures S7a, S7b and S6. Elevation data are from SRTM30_PLUS (electronic supplement). Orange dashed line marks the approximate northern boundary of the Danakil tectonic block (Eagles et al., 2002).

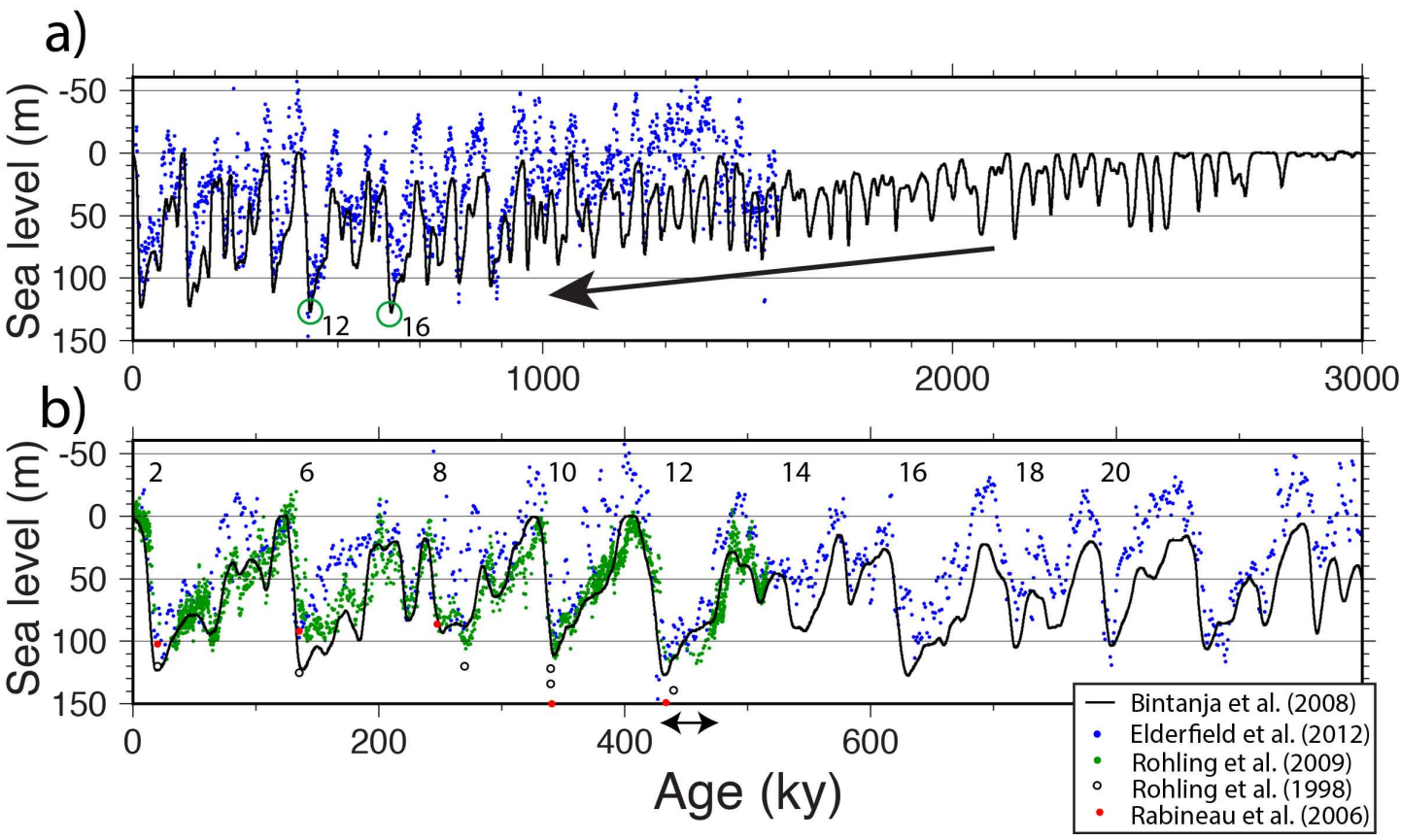

Figure 2. Comparison of sea level reconstructions, emphasizing lowstands. (a) Eustatic sea level from (solid line) model-based deconvolution of deep-sea benthic foraminiferal $\delta^{18} \mathrm{O}$ (Bintanja and van de Wal, 2008) and (blue circles) correction of deep-sea benthic foraminiferal $\delta^{18} 0$ data for temperature effects using Mg/Ca measurements (Elderfield et al., 2012). Arrow highlights increasingly deep sea-level lowstand levels through the early to mid-Pleistocene. Lowstands at MIS 12 and 16 are highlighted. (b) Enlargement of reconstructions in (a), along with (solid green circles) relative sea level derived from Red Sea $\delta^{18} 0$ data (Rohling et al., 2009), (open circles) earlier estimates of relative lowstands from Red Sea $\delta^{18} 0$ data (Rohling et al., 1998) and (red solid circles) 
extreme relative sea-level lowstands at the Mediterranean margin, southern France (Rabineau et al., 2006). Red Sea reconstructions represent relative sea level at Hanish Sill corrected for long-term uplift $\left(\sim 0.02 \mathrm{~m} \mathrm{ky}^{-1}\right)$ and scaled to account for hydro-isostasy (Rohling et al., 2009). Numbers 2-20 across top of (b) mark glacial marine isotope stages. Double-headed arrow highlights the extensive period of lowered sea level during MIS 12 in the Red Sea reconstruction (Rohling et al., 2009).

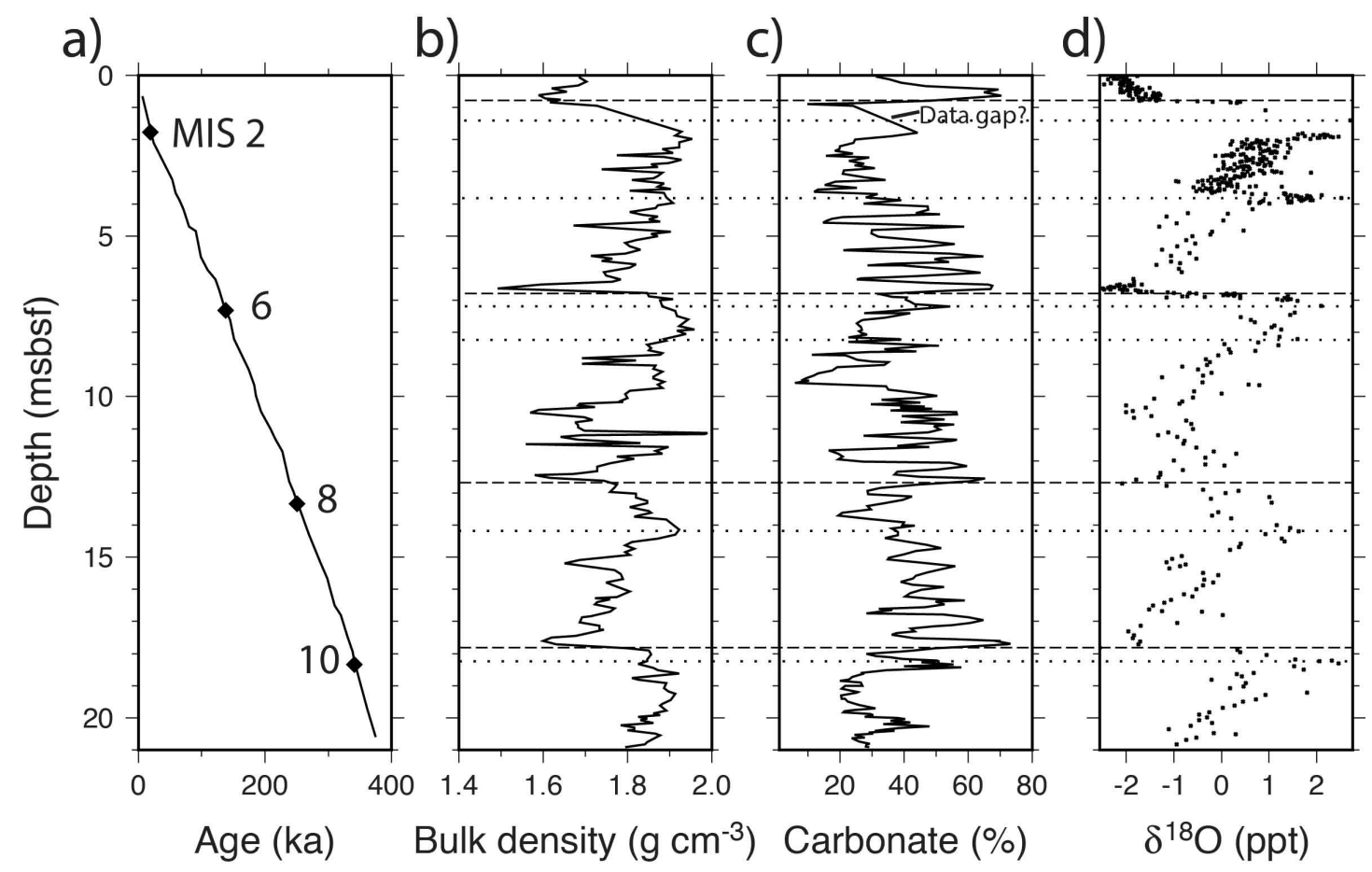

Figure 3. Data from for sediment core GeoTü-KL11. (a) Age model, with diamonds highlighting some glacial marine isotope stages (Hemleben et al., 1996). (b) Saturated bulk density. (c) Carbonate contents. (d) Oxygen isotope data (Hemleben et al., 1996). Data in (b) and (c) were provided by Ch. Hemleben (pers. comm., 2014). Unnaturally straight segments of data in (b) and (c) represent data gaps. Horizontal dotted lines are shown for times of high $\delta^{18} 0$ (sea level lowstands). To help provide visual correlation with Figure 4, dashed 
lines represent times of maximum rate of sea level change (Grant et al., 2014) obtained by visually correlating the $\delta^{18} 0$ variations in (d) with those in Figure $4 a$.

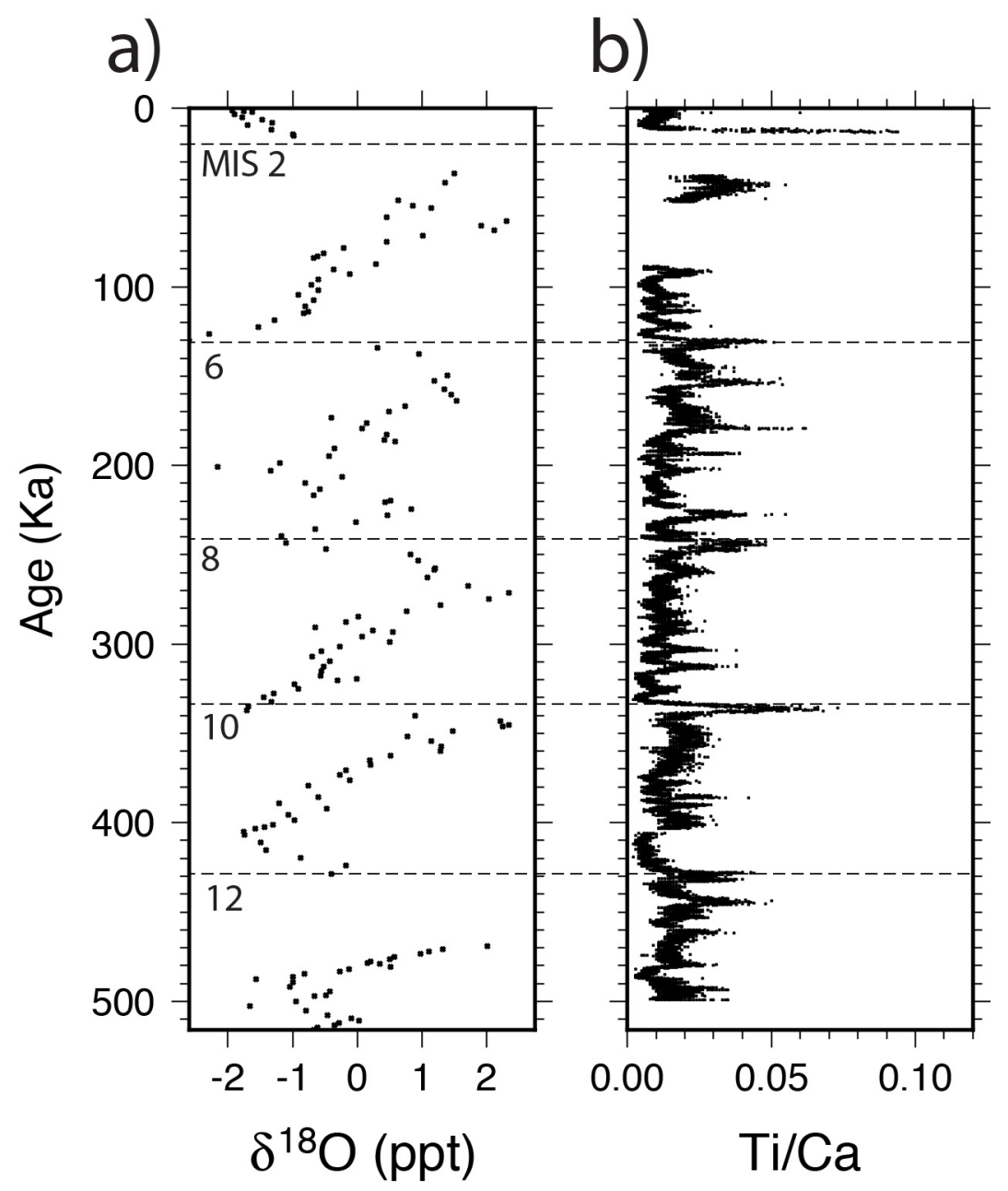

Figure 4. Data from for sediment core GeoTü-KL09: (a) Oxygen isotopes and (b) Bulk sediment Ti/Ca ratio (Roberts et al., 2011). Dashed lines locate times of maximum rate of sea level change (Grant et al., 2014). 
a) Correlation with Rohling et al. (2009) sea level

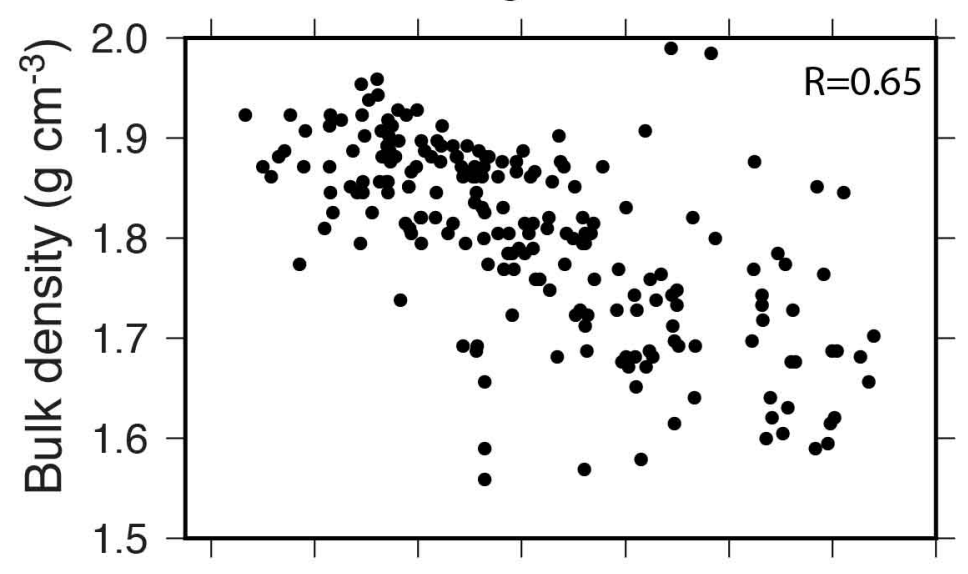

b) Correlation with Bintanja et al. (2008) sea level

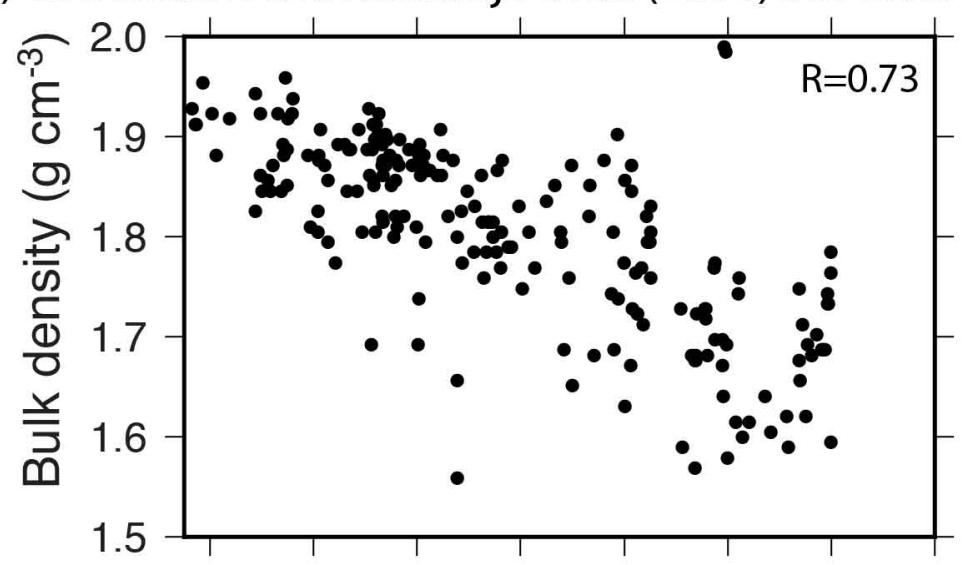

c)

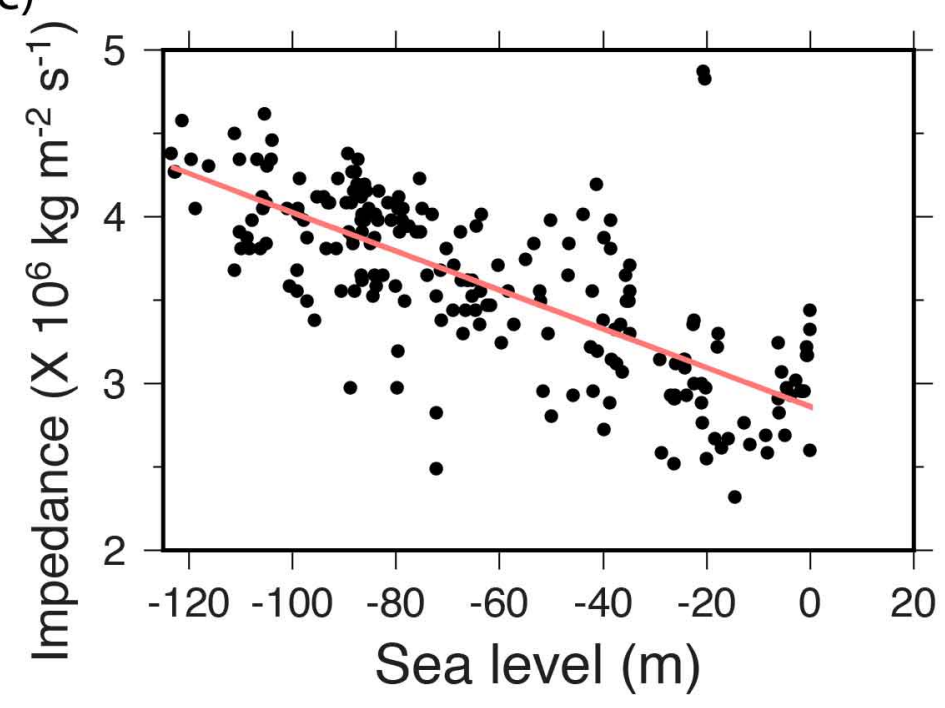

Figure 5. Correlation of sediment bulk density of core KL11 (Figure 3) with sea level. (a) Using the Red Sea relative sea-level reconstruction of Rohling et al. (2009). (b) Using global sea-level reconstruction of Bintanja and van de Wal 
(2008). R-values in (a) and (b) are $\Sigma\left(\left(\mathrm{x}_{\mathrm{i}^{-}}-\bar{x}\right)\left(\mathrm{y}_{\mathrm{i}}-\bar{y}\right)\right) /(\mathrm{n}-1) \sigma_{\mathrm{x}} \sigma_{\mathrm{y}}$, where $x_{i}$ is the ordinate, $y_{i}$ the coordinate, over-bars represent averages, $n$ is the number of data and $\sigma$ is the standard deviation of the ordinate or coordinate. (c) Correlation between estimated impedance and sea level reconstruction of Bintanja and van de Wal (2008) with (red) a robust regression (Wessel and Smith, 1991) trend used in seismogram modeling. 

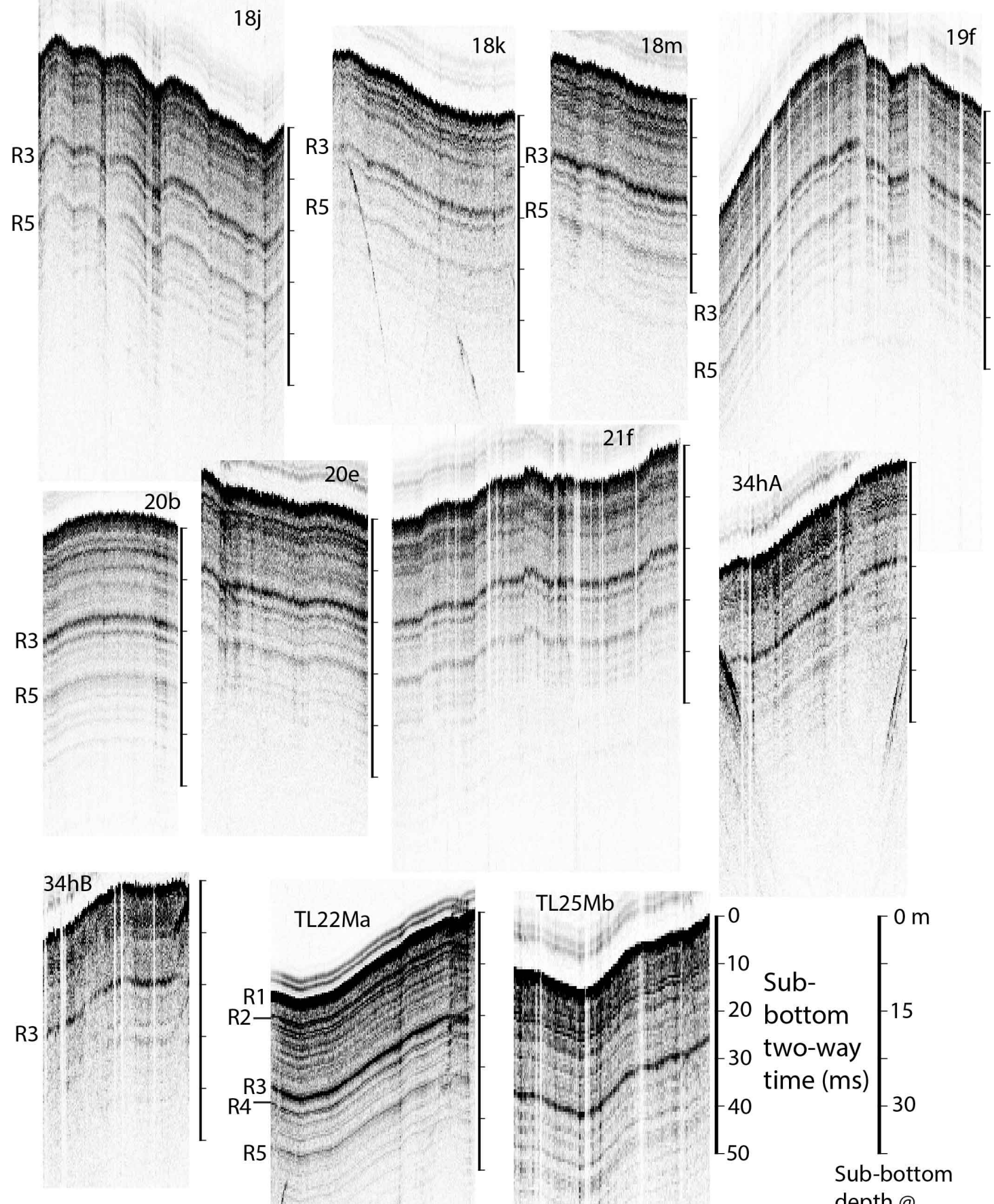

Sub-bottom depth@ $1500 \mathrm{~m} / \mathrm{s}$

Figure 6. Segments of Chirp sediment profiler records collected along the tracklines marked in Figure 7. In these images, black represents strong signal amplitudes. Scale bars to right of each record each span $50 \mathrm{~ms}$ two-way travel 
time or $37.5 \mathrm{~m}$ if sediment velocity is $1500 \mathrm{~m} \mathrm{~s}^{-1}$ (scales are unequal between panels). Annotation R1-R5 are reflections as Figure 9. Data are plotted with extreme vertical exaggeration (e.g., 31:1 for TL22Ma) to highlight the draping shapes of the sequences (following seabed reflection) and emphasize their repeating character.

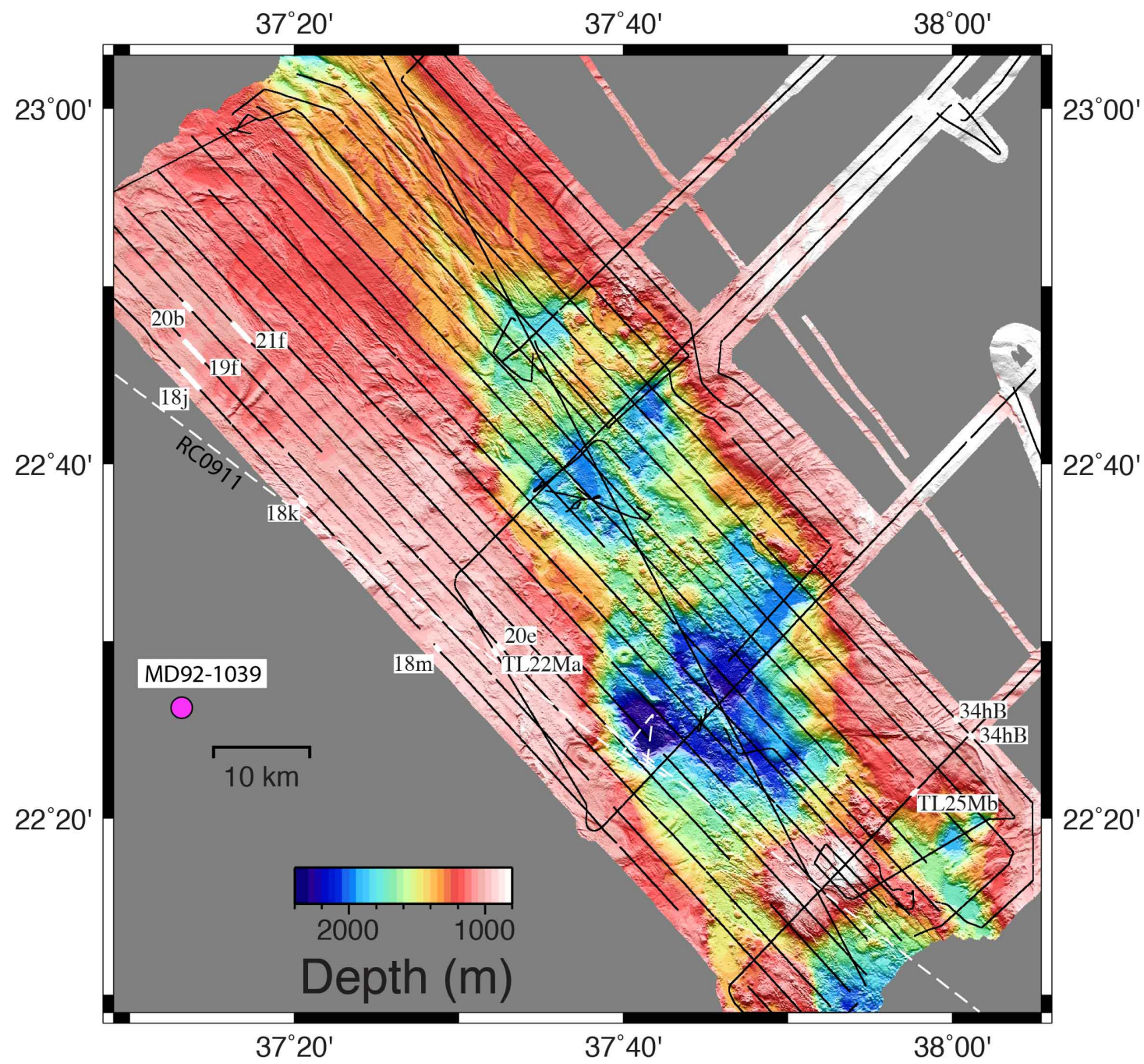

Figure 7. Locations (white line segments superimposed on black track lines) of the segments of RV Urania Chirp data shown in Figure 6. Background is a map of the bathymetry of Thetis Deep (Mitchell et al., 2010). Also shown is the path of 
RV Conrad cruise RC0911 (white dashed line). Magenta-filled circle locates site of core MD92-1039.
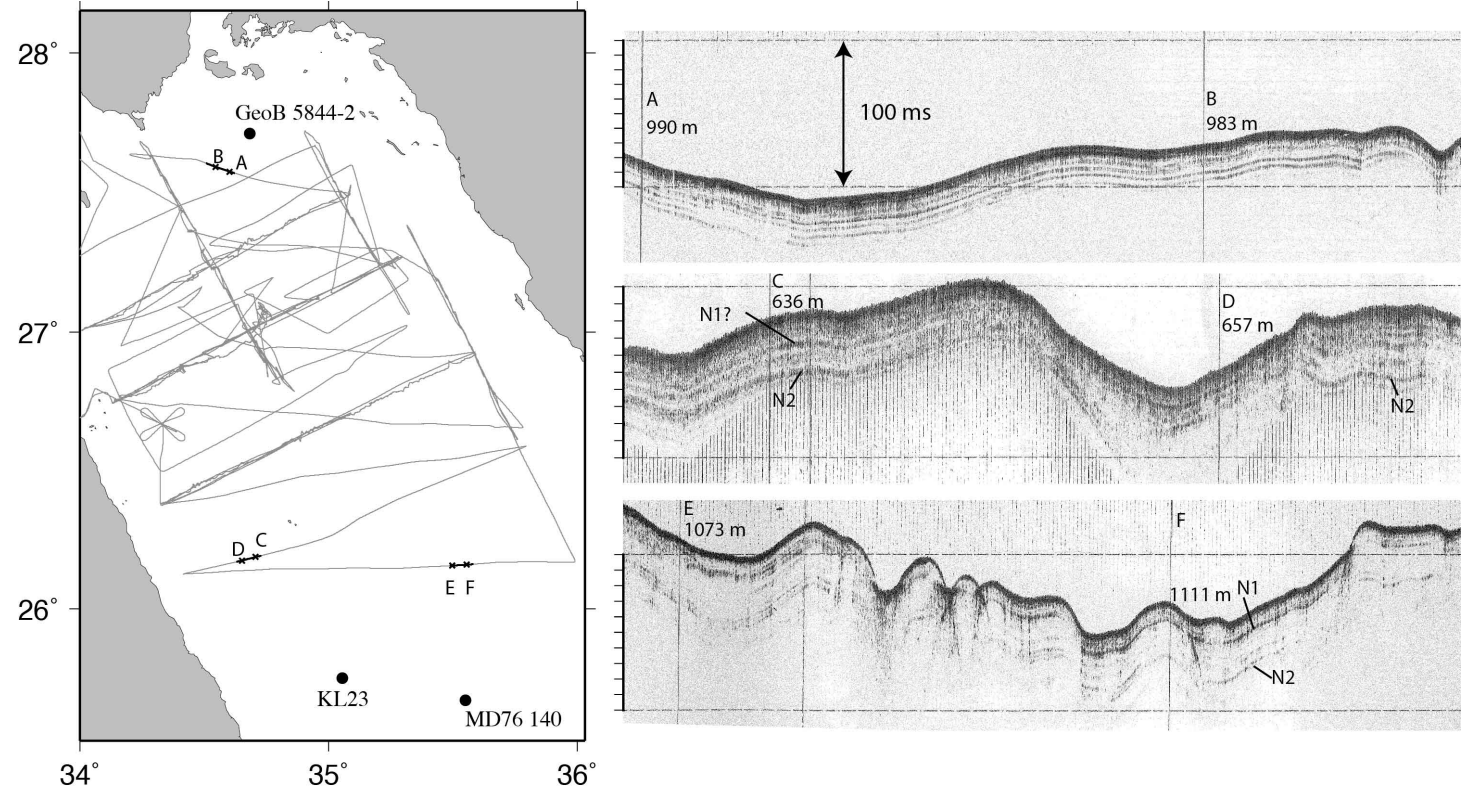

Figure 8. $3.5 \mathrm{kHz}$ sediment profiler data from RV Conrad cruise RC2507. (a)

Tracks (grey lines) with locations of the $3.5 \mathrm{kHz}$ sediment profiler records shown in (b) marked by heavy segments with letters. Solid circles locate sediment cores. Cross marks annotated A-F on map correspond with half-hour time marks on profiler records. (b) Profiler records, with values indicated below the halfhour time marks representing local depths corrected for acoustic velocity variations. 


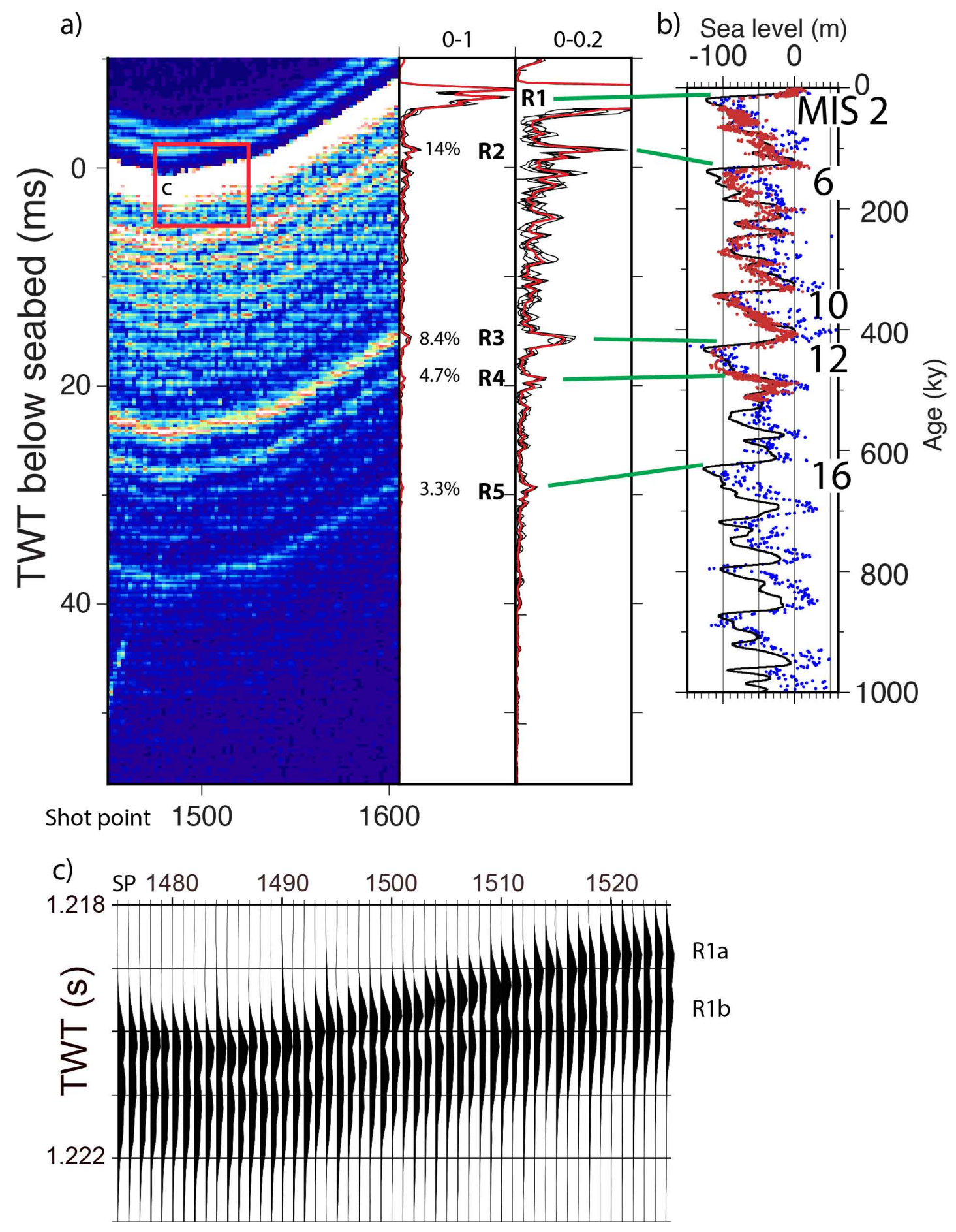

Figure 9. (a) Segment of RV Urania Chirp data (left panel) and extracted trace amplitudes (right graphs) derived from TL22Ma in Figure 6. In each graph on right, six traces are shown (black lines) along with their average (red lines). In left of the two graphs, the reflection amplitudes are scaled to the seabed reflection amplitude. In right graph, the amplitudes are enlarged so that they 
vary over 0 to 0.2 times seabed reflection. Percent values on left graph are the amplitudes of reflections R2-R5 expressed as percentages of maximum amplitude of reflectivity R1 (R1a). (b) Interpreted correspondence between reflections in Chirp data and periods of rapid sea level change. Sea level reconstructions include (solid line) Bintanja and van de Wal (2008), (blue dots) Elderfield et al. (2012) and (red dots) Rohling et al. (2009) (see Figure 2 for details). Numbers 2, 6, 12 and 16 to right are the marine isotope stages. (c) Enlargement of the data (located by red-outlined box in (a)) to show the double peak of reflectivity $\mathrm{R} 1$.

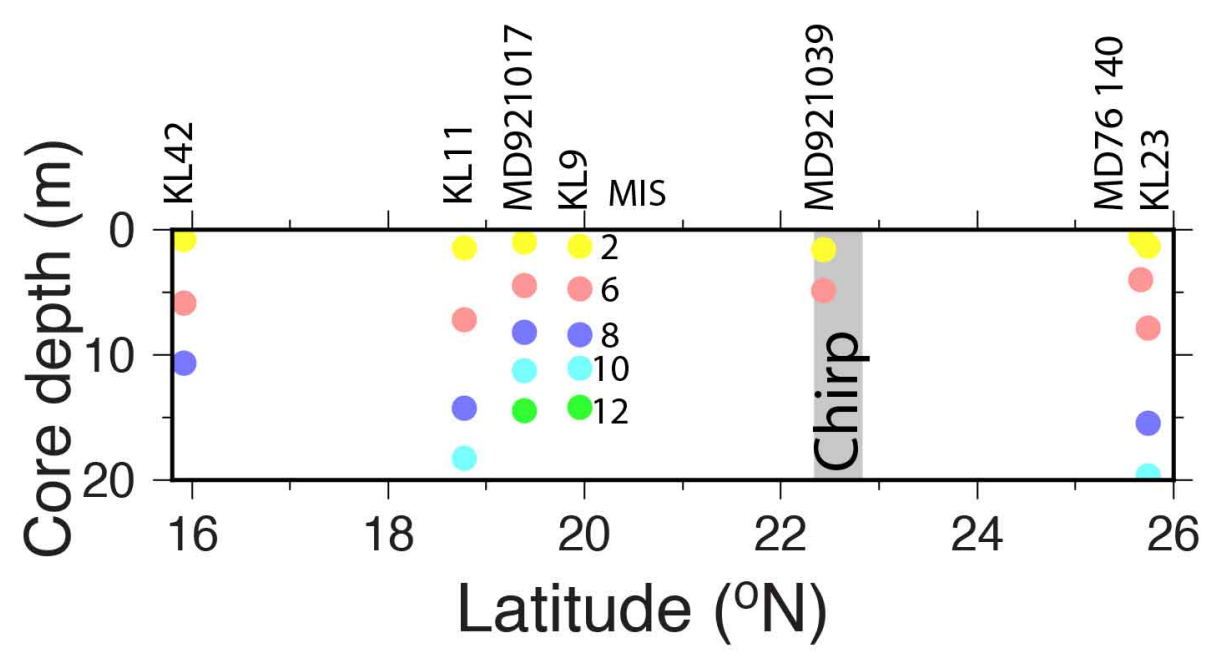

Figure 10. Depths of glacial Marine Isotope Stages (MIS) within sediment cores of the Red Sea, and the latitude of the Chirp records (grey bar). Core sites are shown in Figure 1. Original sources for the $\delta^{18} 0$ stratigraphies are: (KL42) Badawi et al. (2005); (KL11) Hemleben et al. (1996); (MD92-1017) Fenton et al. (2000); (KL9) Rohling et al. (2009); (MD92-1039) Fenton et al. (2000); (MD76140) Almogi-Labin et al. (1986); and (KL23) Badawi et al. (2005). Where samples were missing within glacial maxima but locations were clear, the stage was estimated by interpolation. 


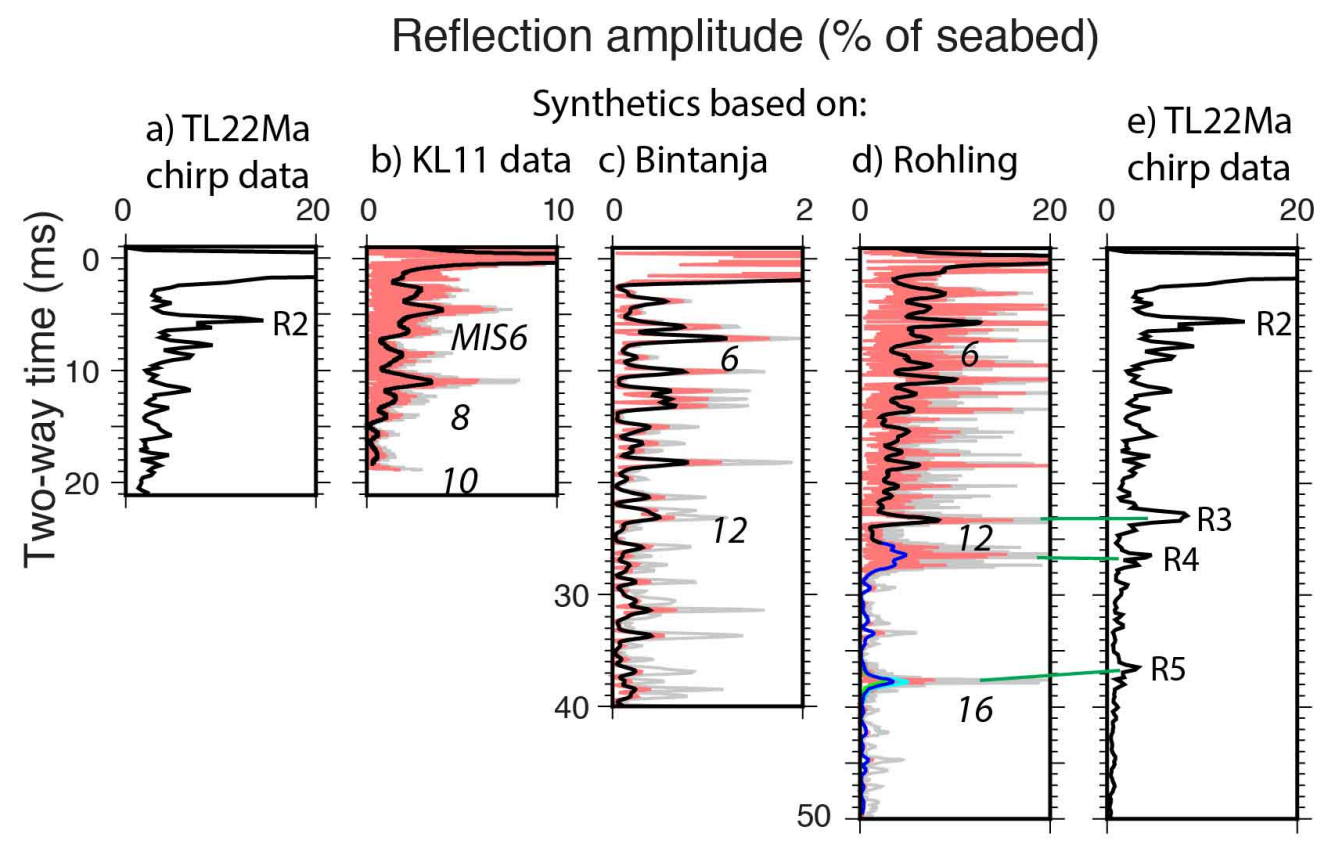

Figure 11. Synthetic seismograms computed to simulate the Urania Chirp data.

Panels (a) and (e) show amplitudes of the TL22Ma data from Figure 9a. The other panels show synthetic seismograms computed from seismic impedance sequences derived from (b) the KL11 core log data (Figure 3), (c) the Bintanja and van de Wal (2008) global sea level and (d) the Rohling et al. (2009) relative sea level reconstruction. To extend the reconstruction in (d) beyond $25 \mathrm{~ms}$ subbottom two-way time, a modified version of the impedance model used for (c) has been appended (see electronic supplement Figure S5), resulting in the blue line. Turquoise and green lines show effect of doubling or halving the rate of impedance and sea level change in that model. In (c)-(e), numbers 6-12 in italics locate the two-way times corresponding to the model isotope stages. See text and Figure S5 for further details.

\section{Electronic supplement}




\section{Chirp system on RV Urania}

Chirp sediment profilers work in a similar way to commercial Vibroseis sweep systems (Telford et al., 1976), differing mainly only in frequency, as the chirp profilers operate at $\mathrm{kHz}$ frequencies (compared with $<100 \mathrm{~Hz}$ often for the Vibroseis systems). The signal processing method originates from the Radar field (Klauder et al., 1960) and has been adapted to work with sediment profilers (Dal Forno and Gasperini, 2008; LeBlanc et al., 1992; Mayer and LeBlanc, 1983; Rona et al., 1973; Schock et al., 1989). In modern Chirp processing, digitally produced linear frequency modulated (FM) acoustic transmissions are used to produce high-resolution images of the sub-bottom layers. To do so, the returned (reflected) signals are correlated with a replica of the transmitted signal so that the effect of the long outgoing sweep signal is compressed in the recorded data (hence in this field the process is described as signal "compression"). The resulting record is similar to that produced with a conventional seismic signal, though with much higher resolution. The correlation step is left to the manufacturer's recording device, since it requires knowledge of the exact outgoing signal, which is proprietary, so only the compressed data are recorded.

The Bentos CHIRP II system installed in the hull of RV Urania as used in the 2005 Red Sea expedition generated a 0.02 s-long $(T)$ signal $w(t)$ with frequency linearly varying from $2000\left(f_{\min }\right)$ to $7000\left(f_{\max }\right) \mathrm{Hz}$ (Figure S1) based on the following formula:

$$
w(t)= \begin{cases}A(t) \cos \left[2 \pi\left(f_{0}+k t\right) t\right] & \forall t \in\left[-\frac{T}{2}, \frac{T}{2}\right] \\ 0 & \text { elsewhere }\end{cases}
$$

where $f_{0}=\left(f_{\min }+f_{\max }\right) / 2$ is the mid-frequency of the bandwidth, $k=\left(f_{\max }-f_{\min }\right) / T$ is the rate of change of frequency with time, and $A(t)$ is the Blackmann-Harris envelope 
function (Harris, 1978) that defines the variation of the signal amplitude with time.

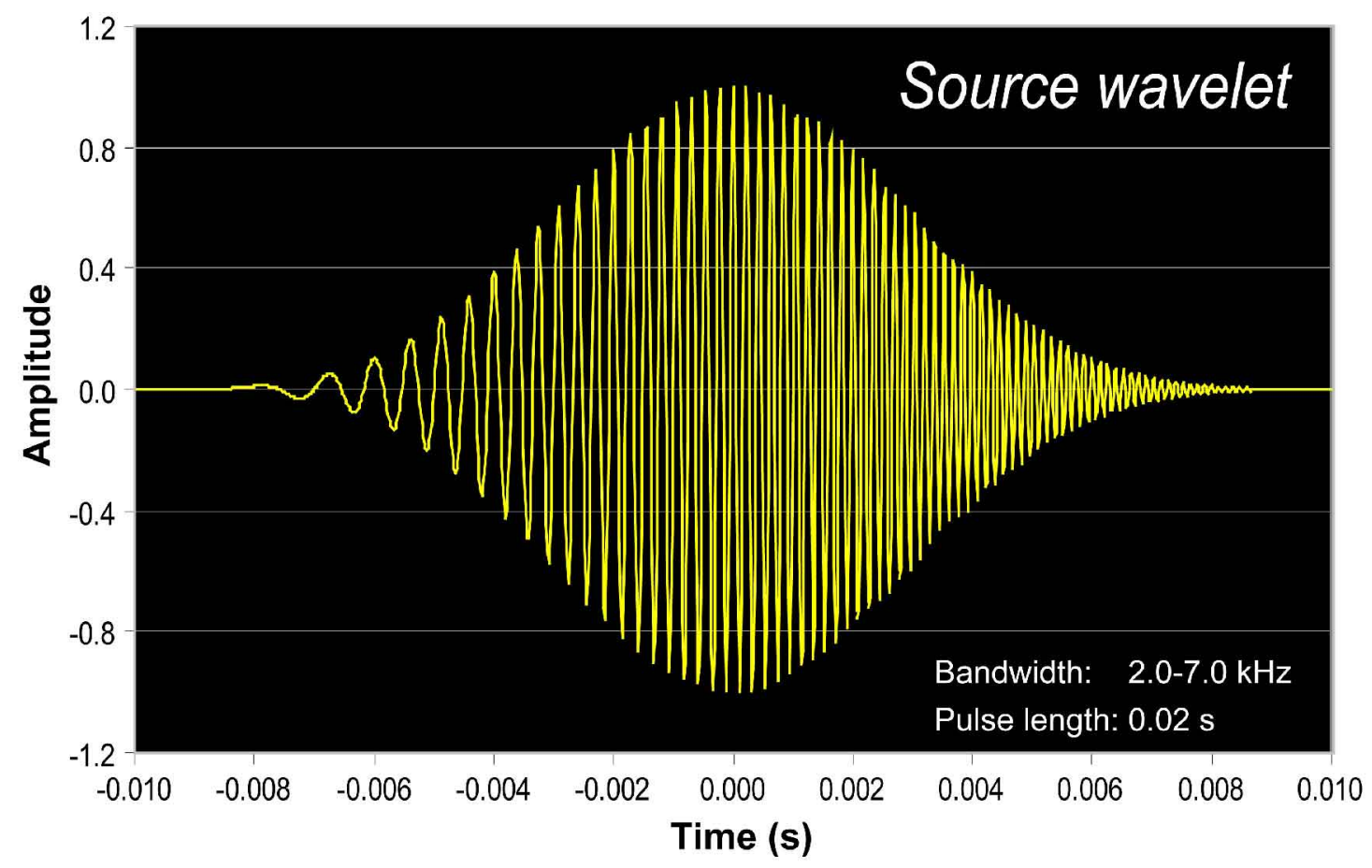

Figure S1. Example of CHIRP II source wavelet. The Blackmann-Harris envelope function used to scale amplitude with time in equation $(S 1)$ is $A(t)=0.359+$ $0.488 \cos (2 \pi t / T)+0.141 \cos (4 \pi t / T)+0.012 \cos (6 \pi t / T)$. 


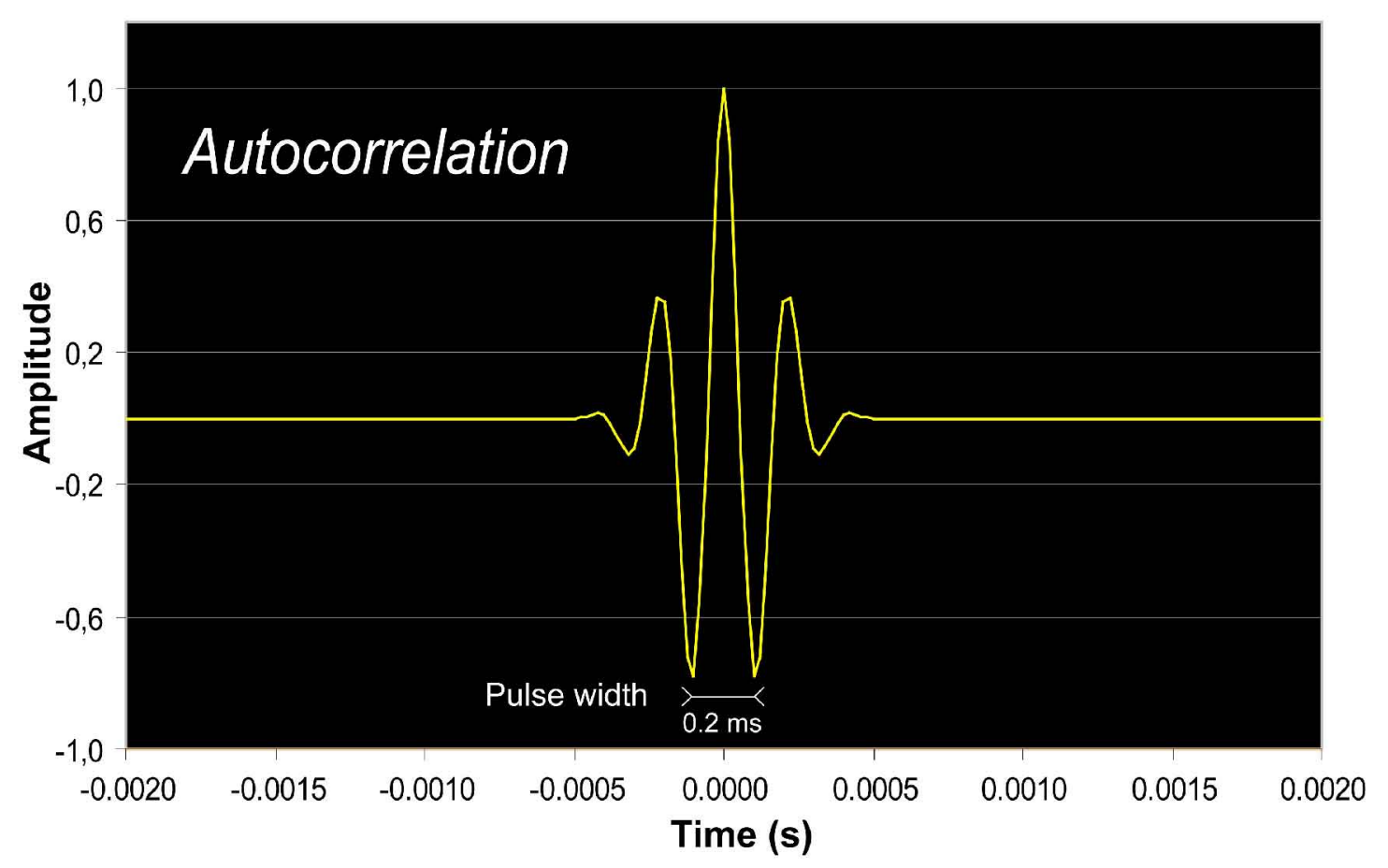

Figure S2. Autocorrelation function of source wavelet shown in Figure S1. The autocorrelation of a chirp pulse (as well as that of Vibroseis systems) is a zero-phase Klauder wavelet.

The autocorrelation function of the chirp sweep shown in Figure S1 is a zero phase Klauder wavelet (Figure S2) and represents the compressed source wavelet $w_{k}(t)$. The signal recorded by the CHIRP II system may be considered the result of the convolution between the compressed source $w_{k}(t)$ with the earth reflectivity series $e(t)$. The sampling rate of the recorded signal is $1 / 32 \mathrm{~ms}$, with a Nyquist frequency of $16 \mathrm{kHz}$ that is much higher than the maximum frequency generated by the system $(7 \mathrm{kHz})$.

Although the exact form of the FM acoustic signal generated by the Bentos CHIRP II system is unknown to us (i.e., $\mathrm{A}(\mathrm{t})$ in equation $(\mathrm{S} 1)$ ), the compressed wavelet (or the "de-chirped" pulse) of the CHIRP II system is likely to be close to that of a Klauder wavelet with the form (Figure S3): 
$w_{k}(t)=\Re e\left\{A \frac{\sin [\pi k(T-t) t]}{\pi k t} \exp \left(2 \pi i f_{0} t\right)\right\} \quad \forall t \in\left[-\frac{T}{2}, \frac{T}{2}\right] \quad(\mathrm{S} 2)$,

where $A$ is a constant and $i^{2}=-1$. The manufacturer's choice of a different weight function $A$ would lead to different side-lobe levels in the following wavelet and potentially a broader peak, but not make major differences to the synthetic seismograms described in this article. Dal Forno and Gasperini (2008) carried out similar modelling but using density and velocity measured from a sediment core. Their successful simulation of the amplitude variation recorded with the same Chirp system as used in our study suggests that the real compressed wavelet is not much different from equation (S2).

The vertical resolution refers to the minimum distance between reflections that can be visually distinguished in an image produced by such systems. In a conventional single-frequency system, the resolution is determined by the pulse length of the transmitted waveform. In a multi-frequency system, it is the bandwidth of the transmitted pulse that sets the system's theoretical resolution. The theoretical chirp profiler resolution is calculated by multiplying the width of the central lobe of the compressed pulse (Figure S3) by the speed of sound in the medium, and dividing the product by two to account for the ping's round trip travel time:

Resolution limit=Pulse width $\mathrm{x}$ Acoustic velocity $/ 2$

Where the Pulse width $=1 /$ Bandwidth .

For example, in the CHIRP II system, the pulse width with a bandwidth of $5 \mathrm{kHz}$ (the system is configured to operate between 2 to $7 \mathrm{kHz}$ ) is $0.0002 \mathrm{~s}$ (Figures $\mathrm{S} 2$ and S3). The signal travelling at about $1540 \mathrm{~m} / \mathrm{s}$ within soft sediments can travel 
$0.308 \mathrm{~m}$ in $0.0002 \mathrm{~s}$. Allowing for the two-way travel time, this results in a oneway distance of $0.154 \mathrm{~m}$. Thus, the theoretical resolution limit in time for a chirp profiler is half of the pulse width, i.e., $0.0001 \mathrm{~s}$ for the system used on Urania in 2005.

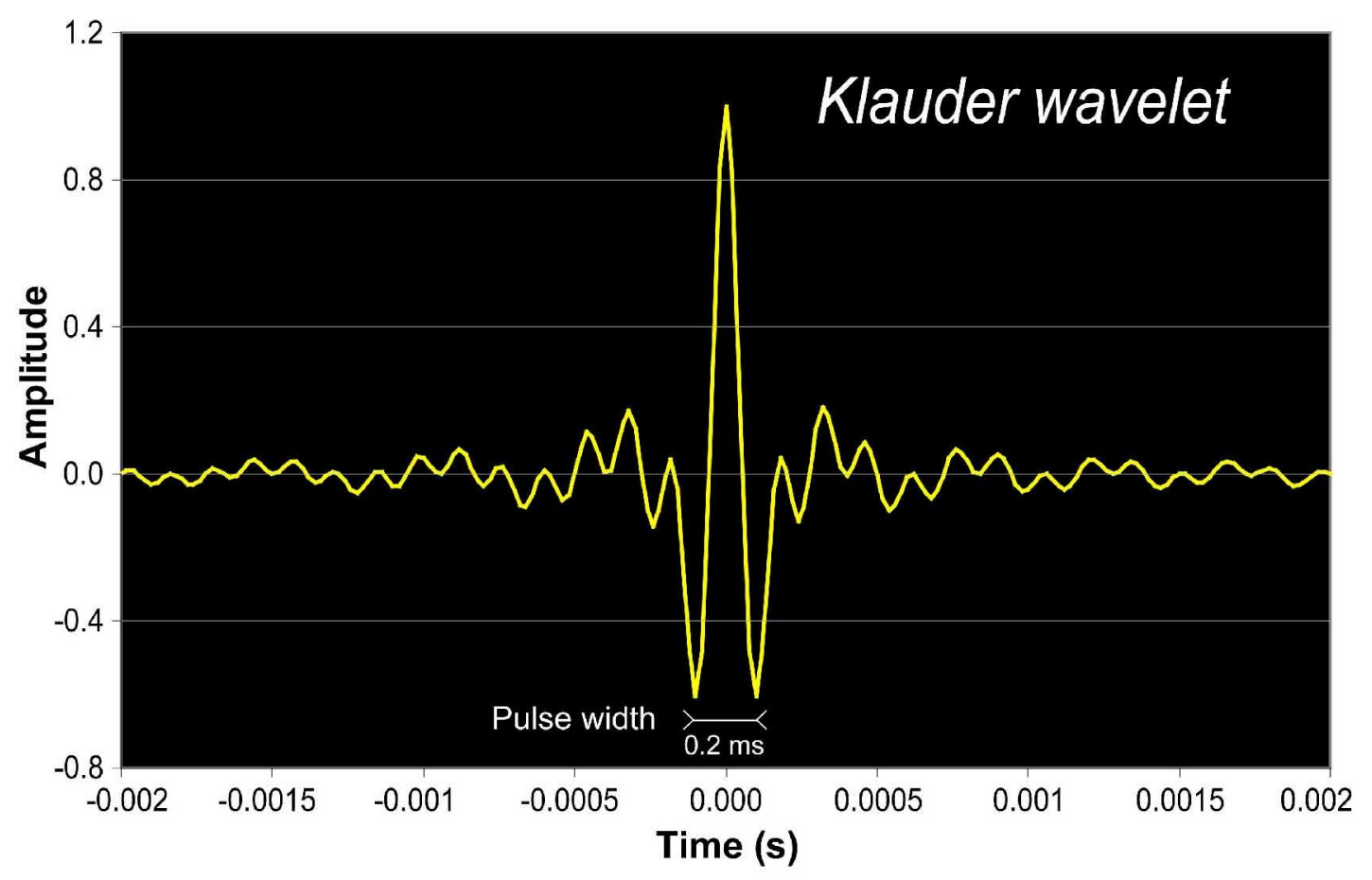

Figure S3. Klauder wavelet generated using equation (S2) with A=1, T=0.02 s, $f_{\min }=2000 \mathrm{~Hz}$ and $f_{\max }=7000 \mathrm{~Hz}$. 


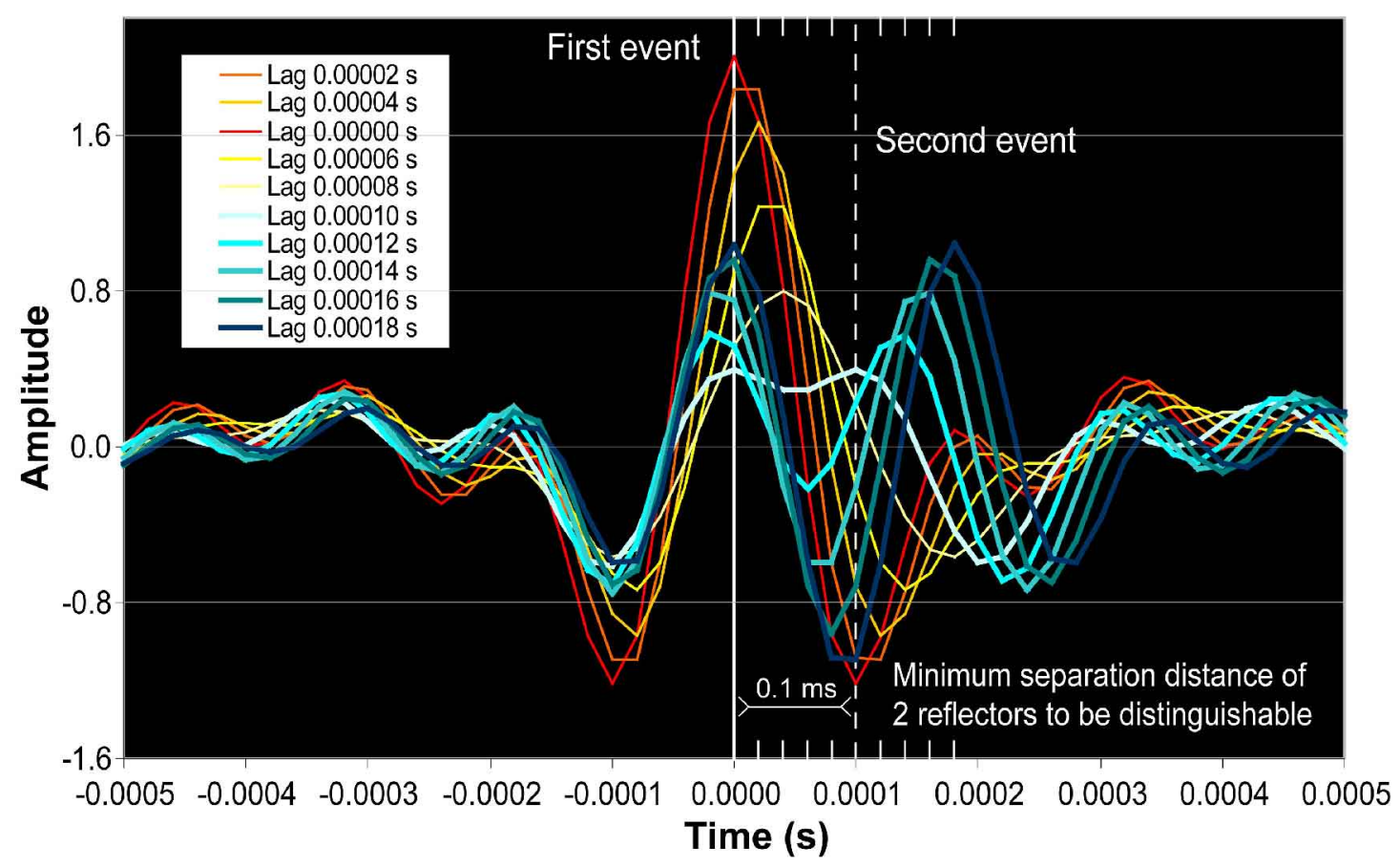

Figure S4. Illustration of CHIRP II resolution. Graphs show reflected signals from two interfaces that are placed at increasing separation distances, with the second interface initially located in the same position of the first interface and then moved down in increments of $0.00002 \mathrm{~s}$ (about $1.54 \mathrm{~cm}$ at a seismic velocity of 1540 $m / s)$.

This is clearly shown in Figure S4, where the Klauder wavelet of Figure S3 is reflected by two interfaces with equal reflection coefficients (each of unity), that are separated by distances increasing in steps of $0.00002 \mathrm{~s}$. Below separations at the resolution limit of $0.0001 \mathrm{~s}$ the reflected signal is stretched due to the smearing of adjacent reflections. Where the separation distance between two reflections is greater than the resolution limit, the resulting two reflected echoes are clearly distinguishable. 
a) Urania chirp compressed source wavelet

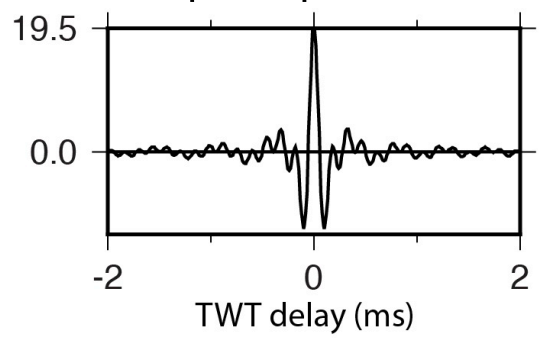

b) Model using KL11 data

Model

TL22Ma data

Bulk density $\left(\mathrm{g} \mathrm{cm}^{-3}\right) \quad \mathrm{R}\left(\mathrm{ms}^{-1}\right)$

Reflection amplitude (\% of seabed)
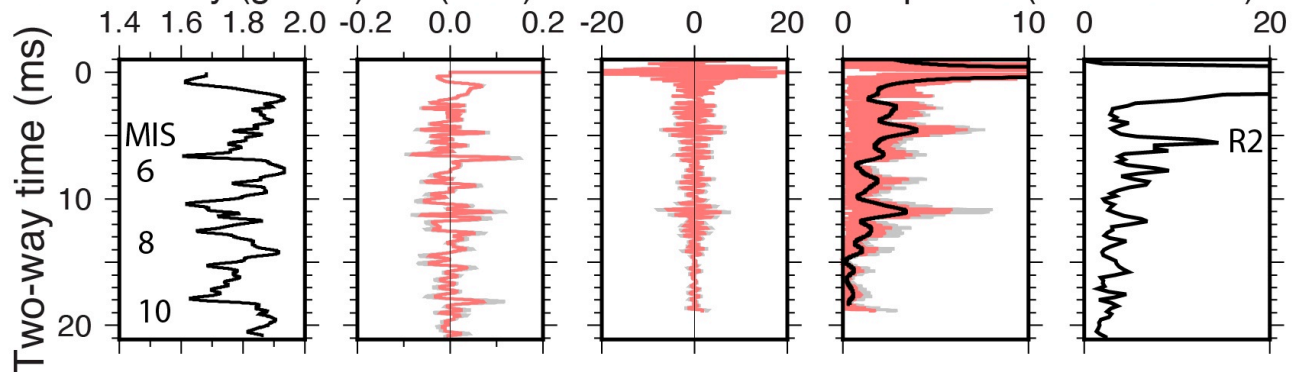

c) Model using Bintanja et al. (2008) sea level curve

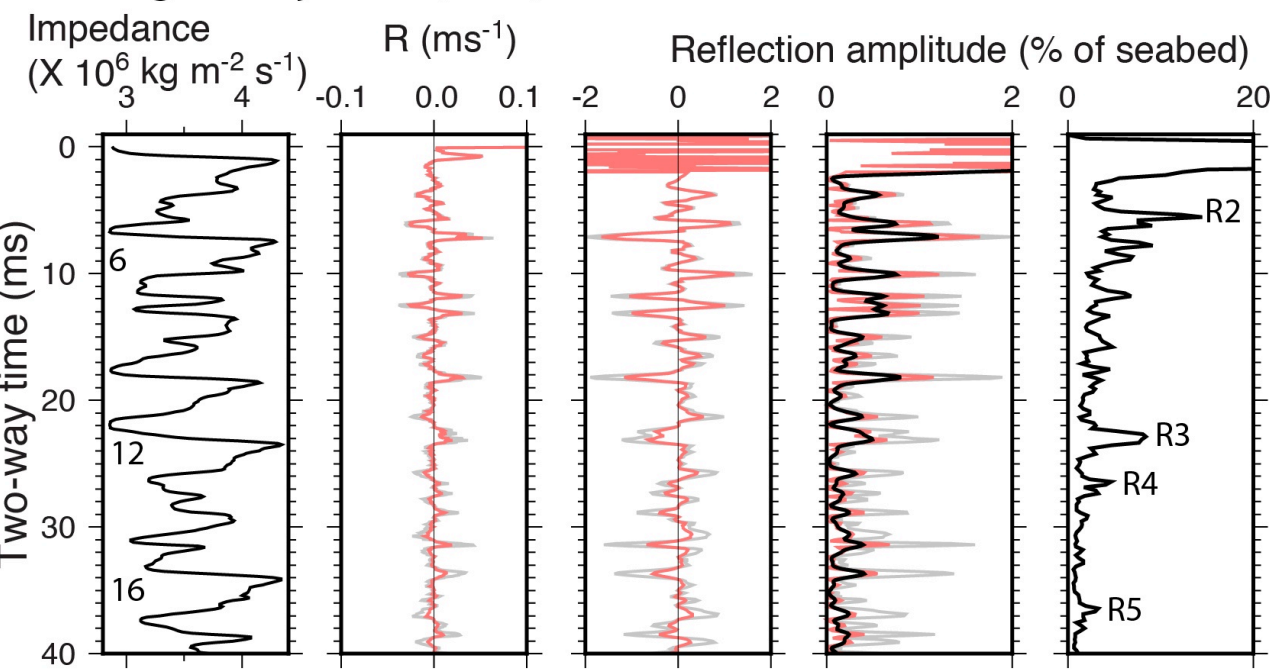

d) Model using Rohling et al. (2009) sea level curve

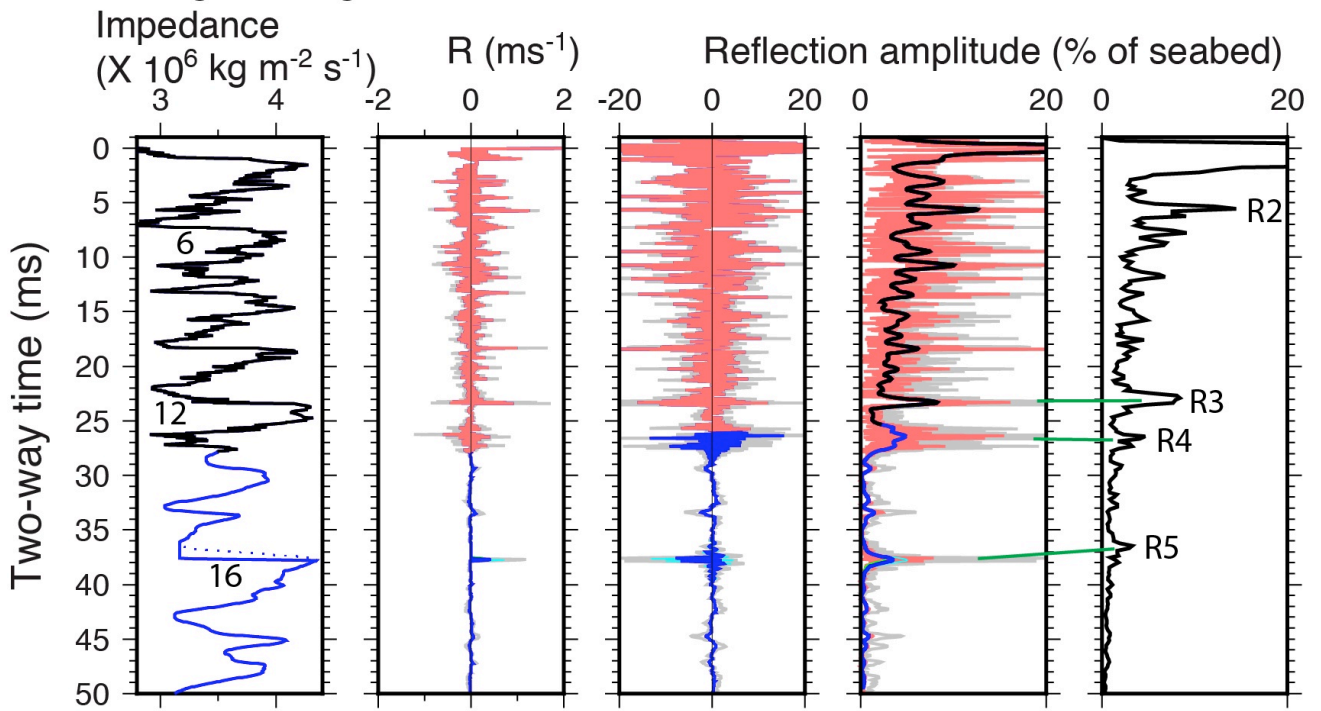


Figure S5. Synthetic seismograms computed to simulate the Urania Chirp data.

(a) Klauder wavelet formed by compression of the Chirp source estimated from the source 2-7 kHz frequency and $20 \mathrm{~ms}$ duration (see Ryan (1994) and text above). (b)-(d) Columns represent (from left to right) the input sediment data series, the reflection coefficient series, the modeled seabed response (result of convoluting the wavelet in (a) with the reflection series), a rectified version of the model and the TL22Ma data from Figure 9. Numbers in left graphs are isotope stages and R2-R5 in the right graphs are the reflections from Figure 9. The synthetic seismograms were computed from (b) the KL11 core density logs (Figure 3), (c) the Bintanja and van de Wal (2008) global sea level and (d) the Rohling et al. (2009) relative sea level reconstruction (Figure 9b). A modified version of the impedance model of (c) has been appended below $28 \mathrm{~ms}$ in (d) as shown in blue to match the amplitude of $R 5$ relative to $R 3$ with adjusted impedance (and hence sea-level) rate of change after MIS 16. Turquoise and green lines show effect of double or half that rate of impedance variation and sea level change.

Assessment of airgun and sparker seismic reflection data

Data of moderately high frequency (compared with datasets with larger airgun chamber sizes) were collected on DV Glomar Challenger through DSDP Sites 226 and 227 with two Bolt airguns (10 and 5 cubic inches). The image shown in Figure S6a originates from the drilling reports (Whitmarsh et al., 1974). To illustrate data resolution, note the double sharp brine reflections in these data, which agree with two or more brine interfaces found elsewhere in Atlantis II Deep (Hartmann et al., 1998)). Further seismic reflection data were collected on RV Conrad during cruise RC0911, using a 25 cubic inch airgun, continuously 
along the solid line in Figure 1. Despite the age of these paper records (1965), they are mostly of good quality. Example panels obtained from the archives at LDE0 are shown in Figures S6b-S6d.

In the Glomar Challenger seismic record (Figure S6a) showing the PP sediments overlying the S-reflection ("S", top of the Miocene evaporites; Ross and Schlee (1973)), the upper PP is strongly reflective, whereas the lower PP is transparent. The seismic data along the continuous RC0911 track (Figure 1) between $15^{\circ} 45^{\prime} \mathrm{N}$ and $22^{\circ} \mathrm{N}$ also show a reflective upper PP and more transparent lower PP (Figure S6b-S6c).

The amplitudes in paper records are not unfortunately possible to assess quantitatively, though we consider it feasible nevertheless to judge whether a displayed reflection amplitude is stronger or weaker than another reflection at a common shot. Whether the decrease in amplitudes with two-way time (hence the PP transparency) is due to attenuation or not depends on whether an adequate time-varied gain (TVG) was originally applied. Unfortunately, no details on TVG for the Glomar Challenger record are available, but the Conrad drum paper recordings from the 1960s often included an adjustable TVG (JK Weissel, pers. comm. 2015). The Conrad paper records include two channels with differing amplifier gains. Figure S6 shows the low gain records because the seabed and S reflections in them are not overly saturated, but the high gain records also show a more transparent lower PP.

A further indication of the effect of TVG and attenuation is provided by the strength of the S reflection. Based on halite velocity $\left(V_{p}\right)$ of $4.2 \mathrm{~km} \mathrm{~s}^{-1}$ and density $(\rho)$ of $2.1 \mathrm{~g} \mathrm{~cm}^{-3}$ (Wheildon et al., 1974) and basal PP $V_{p}$ of $2 \mathrm{~km} \mathrm{~s}^{-1}$ and $\rho$ of $2 \mathrm{~g}$ $\mathrm{cm}^{-3}$ (Whitmarsh et al., 1974), the evaporite-PP interface (S reflection) is 
expected to have a reflection coefficient of $\sim 0.38$. Using a smaller $\rho$ of $1.8 \mathrm{~g} \mathrm{~cm}^{-3}$ for the shallower PP sediments (Figure 3) and a range for $V_{p}$ of $1.5-2 \mathrm{~km} \mathrm{~s}^{-1}$, and water $V_{p}=1.5 \mathrm{~km} \mathrm{~s}^{-1}$ and $\rho=1 \mathrm{~g} \mathrm{~cm}^{-3}$, the seabed reflection coefficient is $\sim 0.29$ 0.41. Thus the two reflections have similar reflection coefficients and, if they appear to have similar amplitudes in the images at a common shot, this implies either that attenuation was modest or that an applied TVG compensated sufficiently for attenuation in the overlying section. In our opinion, the $\mathrm{S}$ reflections in Figure S6 have similar amplitudes to the seabed reflections and therefore, from the logic above, the lower PP is genuinely transparent.

In the main text, we noted a segment of multichannel seismic data in Ehrhardt and Hübscher (2015) where a transparent lower PP remains transparent where the upper PP has been eroded away. We present two further examples in Figure S7, which are digital sparker data collected near to Jeddah (Figure 1). Despite a varied sparker source (P. Feldens pers. comm., 2015), the S reflection can be clearly observed across the section and the transparent lower PP remains transparent where it is elevated closer to the seabed as marked, suggesting it is not an artifact of attenuation and insufficient TVG.

North of $22^{\circ} \mathrm{N}$, the RC0911 data are noisier but one example from the northern Red Sea (Figure S6d) again suggests a more transparent lower PP, although unlike in the southern sector this northern sector profile shows a discrete band of strong reflectivity within the PP. Examining other published records, those of the RV Chain cruises are generally poor (Ross and Schlee, 1973) but profiles 9, 10 and 13 of Phillips and Ross (1970) show a less reflective lower PP in the central Red Sea $\left(18^{\circ}-21^{\circ} \mathrm{N}\right)$. As with the Conrad RC0911 data, this pattern seems less clear to the north of $\sim 23^{\circ} \mathrm{N}$, where both the upper and lower 
PP appear to be reflective. Seismic reflection data with reflective lower PP in the northern Red Sea are shown in Cochran et al. (1986, 1991), Coutelle et al. (1991), Guennoc et al. (1988) and Martinez and Cochran (1988). In contrast, data of Ehrhardt et al. (2005) also from the northern Red Sea show several sections in which the lower PP is more transparent and a prominent S reflection demonstrates that this is not due to inadequate TVG. Further sections of data from RV Urania and MV Bannock with both reflective and transparent sections of lower PP are shown in Mitchell et al. (in press). In almost all these different data, the uppermost PP is highly reflective.

We interpret the reflective uppermost PP as originating from the alternating aragonite-rich 'hard' layers and varied terrigenous input. Where the lowermost PP is reflective, we suggest this arises mainly from varied terrigenous input, in particular, aeolian dust. The transparent sections then arise where the terrigenous component is either minor or more uniform. Sediment dates increase non-linearly with depth at DSDP Site 227 (Whitmarsh et al., 1974), suggesting an age greater than 4 Ma at around mid-depth in the PP interval there (revised dates in www.geomapapp.org; also see below). Hence, the transparent base of the PP sequence (Figure S6a) likely represents the lower Pliocene (prior to $4 \mathrm{Ma}$ ) at this site. 
a) DV Glomar Challenger, central Red Sea

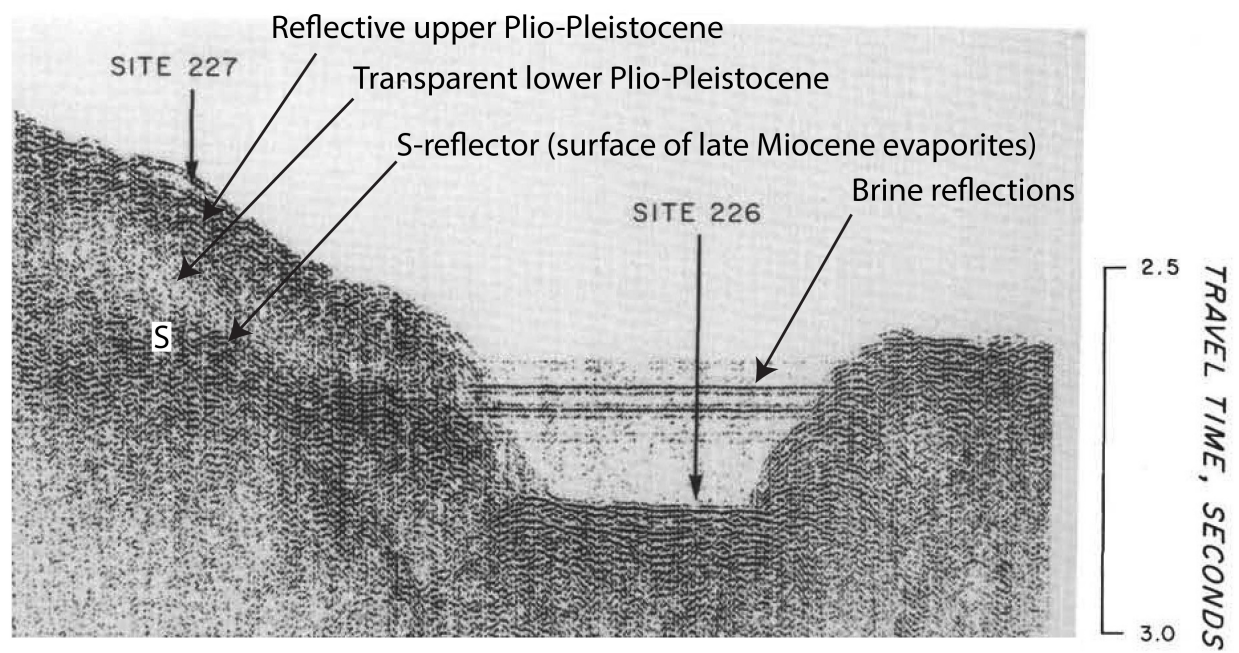

b) RV Conrad RC0911, southern Red Sea d) RV Conrad RC0911, northern Red Sea
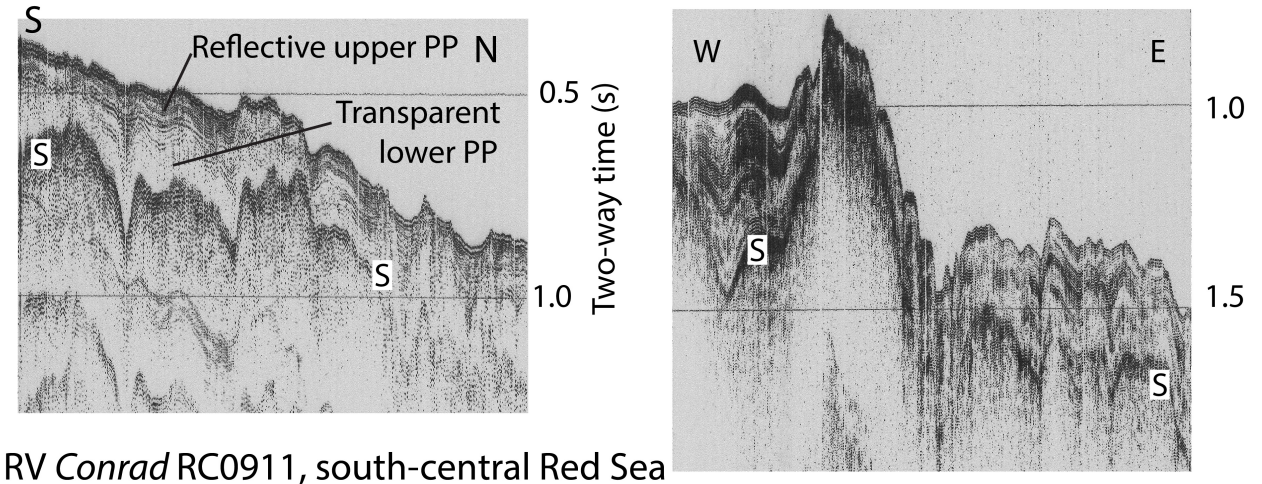

c) RV Conrad RC0911, south-central Red Sea

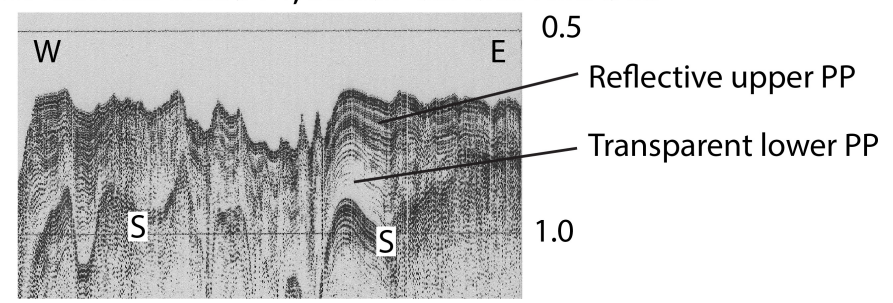

Figure S6. (a) Seismic reflection image collected on DV Glomar Challenger through DSDP Sites 226 and 227 (Whitmarsh et al., 1974). For horizontal scale, the distance between the drill sites is $4.35 \mathrm{~km}$. (b)-(d) Profiles collected on RV Conrad during cruise RC0911. The segments of data shown correspond with the red lines marked along the Conrad RC0911 track in Figure 1.

Figure S7a: 


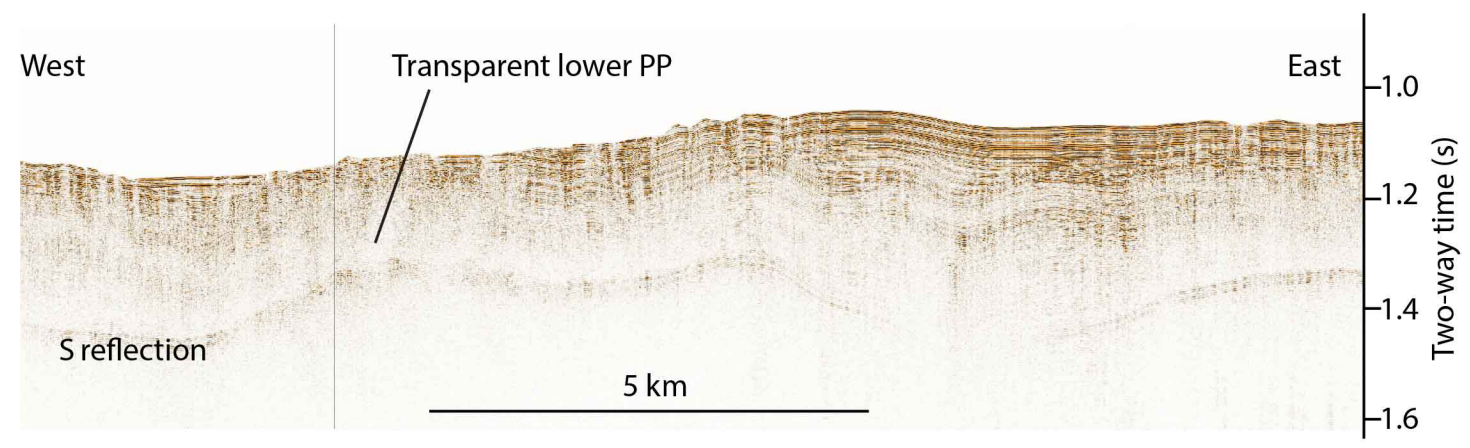

Figure S7b:

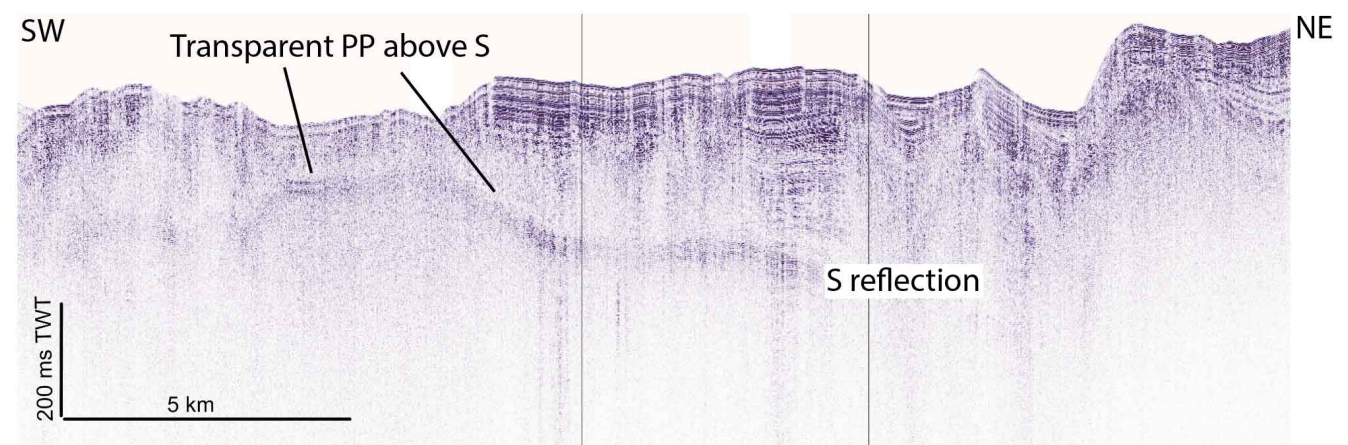

Figure S7. Examples of sparker seismic data collected near Jeddah (Figure 1) kindly provided by Peter Feldens of the University of Kiel, Germany. S: S-reflection (top of the Miocene evaporites). (a) Data collected on RV Poseidon (Schmidt et al., 2011) and (b) data collected on RV Pelagia (Schmidt et al., 2013). Both lines were acquired as part of the Jeddah Transect Project, a collaboration between King Abdulaziz University and Helmholtz-Center for Ocean Research GEOMAR Kiel funded by King Abdulaziz University (KAU) Jeddah, Saudi Arabia. 


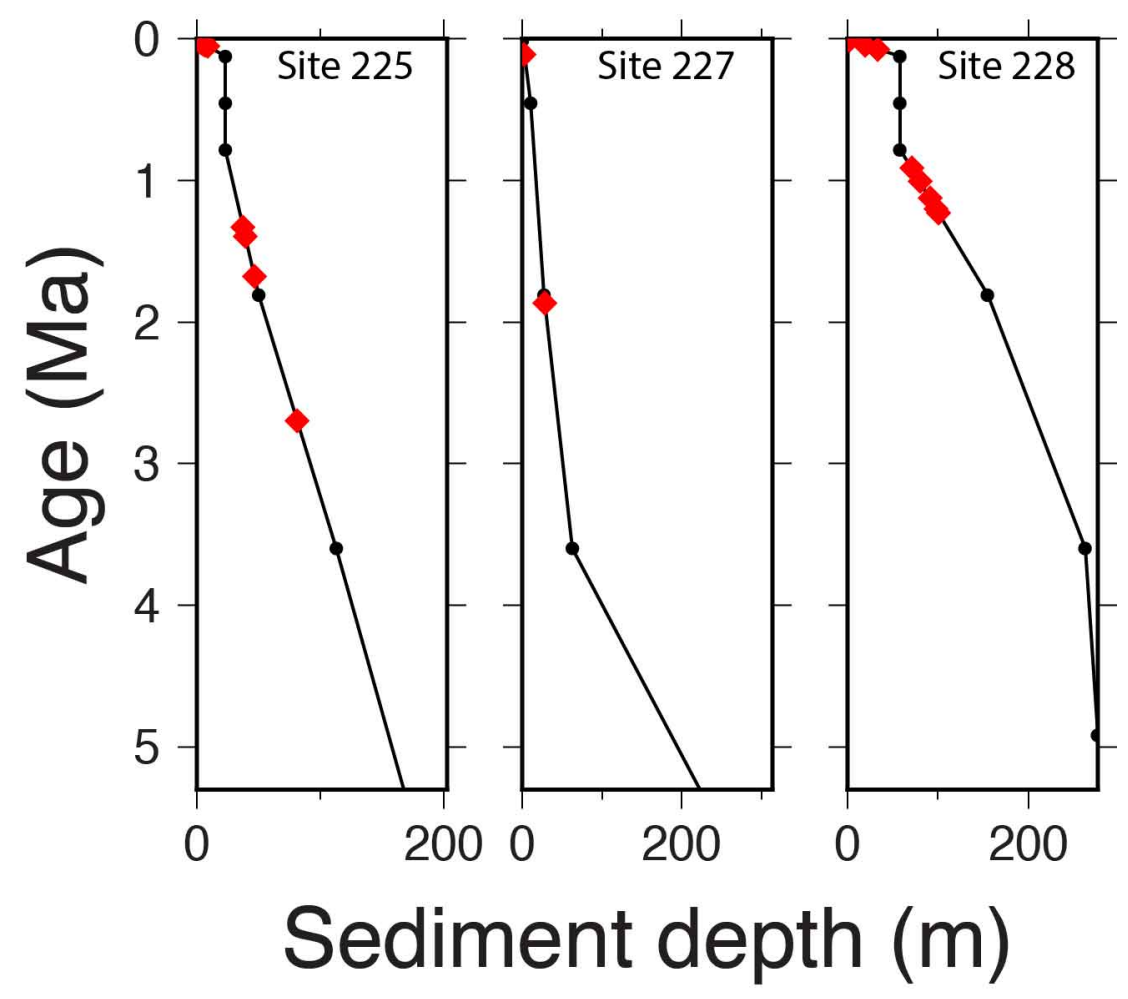

Figure S8. Red diamond symbols: depth distribution of lithified aragonite and magnesium-calcite according to Stoffers and Ross (1974). Occurrences of these 'hard layers' have been assigned sediment ages using stratigraphic data (solid black circles connected by solid lines) updated to modern ages provided within the GeoMapApp data browser (www.geomapapp.org; WBF Ryan, pers. comm., 2009).

Other notes

Elevation data used in Figure 1 are from Becker et al. (2009). Figures were created with the aid of the "GMT" software system (Wessel and Smith, 1991). Approximate northern limit of the Danakil tectonic platelet marked with orange dashed line on Figure 1 was also based on study of chron 2A seafloor spreading magnetic anomalies in the Red Sea by Chu and Gordon (1998), who constrained the plate triple junction between the Danakil platelet, Nubia and Arabia to lie between $17.4^{\circ} \mathrm{N}$ and $18.7^{\circ} \mathrm{N}$. 
Becker, J.J., Sandwell, D.T., Smith, W.H.F., Braud, J., Binder, B., Depner, J., Fabre, D., Factor, J., Ingalls, S., Kim, S.-H., Ladner, R., Marks, K., Nelson, S., Pharaoh, A., Trimmer, R., Von Rosenberg, J., Wallace, G., Weatherall, P., 2009. Global Bathymetry and Elevation Data at 30 Arc Seconds Resolution: SRTM30_PLUS. Marine Geodesy 32, 355-371.

Bintanja, R., van de Wal, R.S.W., 2008. North American ice-sheet dynamics and the onset of 100,000-year glacial cycles. Nature 454, 869-872.

Chu, D., Gordon, R.G., 1998. Current plate motions across the Red Sea. Geophys. J. Int. 135, 313-328.

Cochran, J., Martinez, F., Steckler, M.S., Hobart, M.A., 1986. Conrad Deep: A northern Red Sea deep. Origin and implication for continental rifting. Earth Planet. Sci. Lett. 78, 18-32.

Cochran, J.R., Gaulier, J.M., Le Pichon, X., 1991. Crustal structure and the mechanism of extension in the northern Red Sea: Constraints from gravity anomalies. Tectonics 10, 1018-1037.

Coutelle, A., Pautot, G., Guennoc, P., 1991. The structural setting of the Red Sea axial valley and deeps: implications for crustal thinning processes. Tectonophys. 198, 395-409.

Dal Forno, G., Gasperini, L., 2008. ChirCor: A new tool for generating chirp-sonar seismograms. Comput. Geosc. 34, 103-114.

Ehrhardt, A., Hübscher, C., 2015. The northern Red Sea in transition from rifting to drifting - Lessons learned from ocean Deeps, in: Rasul, N.M.A., Stewart, I.C.F. (Eds.), The Red Sea: The formation, morphology, oceanography and environment of a young ocean basin. Springer-Verlag, Berlin Heidelberg, pp. 99-121.

Ehrhardt, A., Hübscher, C., Gajewski, D., 2005. Conrad Deep, Northern Red Sea: 
Development of an early stage ocean deep within the axial depression. Tectonophys. 411 , $19-40$.

Guennoc, P., Pautot, G., Coutelle, A., 1988. Surficial structures of the northern Red Sea axial valley from $23^{\circ} \mathrm{N}$ to $28^{\circ} \mathrm{N}$ : time and space evolution of neo-oceanic structures. Tectonophys. 153, 1-23.

Harris, F.J., 1978. On the use of windows for harmonic analysis with discrete Fourier transform. Proc. IEEE 66, 51-83.

Hartmann, M., Scholten, J.C., Stoffers, P., Wehner, F., 1998. Hydrographic structure of brine-filled deeps in the Red Sea - new results from the Shaban, Kebrit, Atlantis II, and Discovery Deep. Mar. Geol. 144, 311-330.

Klauder, J.R., Price, A.C., Darlington, S., Albersheim, W.J., 1960. The theory and design of chirp radars. The Bell System Technical Journal 39, 745-808.

LeBlanc, L.R., Mayer, L., Rufino, M., Schock, S.G., King, J., 1992. Marine sediment classification using chirp sonar. J. Acoust. Soc. Am. 91, 107-115.

Martinez, F., Cochran, J.R., 1988. Structure and tectonics in the northern Red Sea: catching a continental margin between rifting and drifting. Tectonophys. 150, 1-32.

Mayer, L.A., LeBlanc, L.R., 1983. The chirp sonar: a new, quantitative high resolution sub-bottom profiling system, in: Pace, N.G. (Ed.), Acoustics and the Sea Bed. University of Bath, Bath, p. 367.

Mitchell, N.C., Ligi, M., Feldens, P., Hübscher, C., in press. Deformation of a young salt giant: regional topography of the Red Sea Miocene evaporites. Basin Res. http://dx.doi.org/10.1016/j.eps1.2015.08.037

Rohling, E.J., Grant, K., Bolshaw, M., Roberts, A.P., Siddall, M., Hemleben, C., Kucera, M., 2009. Antarctic temperature and global sea level closely coupled over the past five glacial cycles. Nature Geosci. 2, 500-504. 
Rona, P.A., Parvulescu, A., Liang, W., Lauter, C.A., 1973. Development and preliminary test of a 1000-Hertz pulse compression seismic reflection profiling system. J. Geophys. Res. 78, 8577-8583.

Ross, D.A., Schlee, J., 1973. Shallow structure and geologic development of the southern Red Sea. Geol. Soc. Am. Bull. 84, 3827-3848.

Ryan, H., 1994. Ricker, Ormsby, Klauder, Butterworth - a choice of wavelets. CSEG Recorder September, 8-9.

Schmidt, M., Al-Farawati, R., Al-Aidaroos, A., Kürten, B. (eds.), 2013. RV PELAGIA Fahrtbericht / Cruise Report 64PE350/64PE351 - JEDDAH-TRANSECT ; 08.03. 05.04.2012 Jeddah - Jeddah, 06.04 - 22.04.2012 Jeddah - Duba, GEOMAR Report, N. Ser. 005. GEOMAR Helmholtz-Zentrum für Ozeanforschung, Kiel, Kiel, Germany, 154 pp., doi:110.3289/GEOMAR_REP_NS_3285_2013.

Schmidt, M., Devey, C., Eisenhauer, A., cruise participants, 2011. FS Poseidon cruise report P408. Christian-Albrechts University of Kiel, Kiel, Germany, 80 pp..

Schock, S.G., LeBlanc, L.R., Mayer, L.A., 1989. Chirp subbottom profiler for quantitative sediment analysis. Geophysics 54, 445-450.

Stoffers, P., Ross, D.A., 1974. Sedimentary history of the Red Sea. in: Whitmarsh, R.B., O.E. Weser, D.A. Ross, et al., Initial reports of the Deep Sea Drilling Project U.S. Government Printing Office 23, 849-865.

Telford, W.M., Geldart, L.P., Sheriff, R.E., Keys, D.A., 1976. Applied Geophysics. Cambridge University Press, New York.

Wessel, P., Smith, W.H.F., 1991. Free software helps map and display data. Eos, Transactions, American Geophysical Union 72, 441.

Wheildon, J., Evans, T.R., Girdler, R.W., 1974. Thermal conductivity, density, and sonic velocity measurements of samples of anhydrite and halite from Sites 225 and 227, in: 
Whitmarsh, R.B., Weser, O.E., Ross, D.A., al., e. (Eds.), Initial Reports of the Deep Sea

Drilling Project, Vol. 23. U.S. Govt. Printing Office, Washington, D.C., pp. 909-911.

Whitmarsh, R.B., Weser, O.E., Ross, D.A., 1974. Initial Reports of the Deep Sea

Drilling Project, 23B. U. S. Government Printing Office, Washington, D. C. 